\title{
INFLUENCE OF MODE INTERACTIONS ON INELASTIC BUCKLING EFFECTIVE STRESSES IN THIN-WALLED COLUMNS USING FINITE STRIP METHOD
}

\author{
D.D. Milašinović ${ }^{1}$ \\ P. Marić ${ }^{2}$ \\ Ž. Živanov ${ }^{2}$ \\ M. Hajduković ${ }^{2}$
}

UDK: 624.042.3.072.31

DOI: $10.14415 /$ konferencijaGFS2019.036

Summary: The inelastic buckling, free vibration and damage of prismatic thin-walled columns, considering two sources of non-linearity (geometrical non-linearity due to large deflection and material non-linearity due to inelastic behaviour), are analysed by implementing the semi-analytical finite strip method (FSM). A very basic continuum damage model with one damage parameter is implemented in conjunction with a mathematical material modelling approach named rheological-dynamical analogy $(R D A)$ in order to address stiffness reduction due to inelastic behaviour. The RDA is a type of inelastic analysis, which transforms one category of very complicated material non-linear problems to simpler linear dynamical problems using modal analysis. The effective stress, as defined in the damage mechanics, is used in this paper. An analysis of damaged composite thin-walled wide-flange columns made of a polymer resin, which is reinforced with fibrous material, is carried out. Numerical examples computed by application of extensive hybrid parallelization present the influence of mode interactions on the damage variables and effective stresses in thin-walled columns.

Keywords: Thin-walled columns, FSM, inelastic buckling, free vibration, RDA, mode interactions, damage variables, effective stresses, hybrid parallelization.

\section{INTRODUCTION}

The thin-walled structures are structures which are generally made by joining flat plates at their edges. An important sub-set of these structures, which are the main concern of this paper, are essentially prismatic forms that can have some stiffeners, such as those used in column members, stiffened slabs and box girders. The analysis of the behaviour of these structures is approached using the FSM. The FSM is based on the basis functions (or eigenfunctions), which are derived from the solution of the beam differential equation of transverse vibration, and proved to be an efficient tool for

\footnotetext{
Faculty of Civil Engineering Subotica, University of Novi Sad, Serbia

Faculty of Technical Science, University of Novi Sad, Serbia
} 
analysing a great deal of structures for which both geometry and material properties can be considered as constant along a main direction. This method was pioneered by Cheung [1], who combined the plane elasticity and the Kirchhoff plate theory. Wang and Dawe [2] have applied the elastic geometrically nonlinear FSM to the large deflection and post-overall-buckling analysis of diaphragm-supported plate structures.

Current versions of FSM are capable of modelling the plates with different thickness and material properties along the longitudinal direction of the strip. Naderian at al. proposed an integrated finite strip discretization scheme for the flat shell spline finite strip for modelling of long-span cable-stayed bridges [3]. This approach of FSM is a very efficient technique and its application to the dynamic inelastic buckling of thin-walled structures is highly appreciated. Kwon and Hancock [4] developed the spline FSM to handle local, distortional and overall buckling modes in post-buckling range.

Interaction of two types of column buckling (failure) in thin-walled structures, local and global (Euler) column buckling, may generate an unstable coupled mode, rendering the structure highly sensitive to imperfections. The geometrically nonlinear harmonic coupled FSM (HCFSM) [5, 6] is also one of the many procedures that can be applied to analyse the large deflection and buckling-mode interaction of thin-walled structures. An analysis of the buckling-mode interaction is carried out in [7], taking into account the viscoelastic behaviour of material. Furthermore, to address these issues, strips with nonuniform characteristics in the longitudinal direction and transverse stiffeners have been used in geometrical non-linear static analysis of prismatic shells [8]. A very important effort for improvement of this approach is done via parallelization. Application of parallelization was necessary to overpower the increased computational complexity, caused by coupling of all series terms in the HCFSM formulation, by the usage of the high number of modes, as well as by the need to calculate a large number of different integrals. It was inevitable to combine different parallelization models - MPI and OpenMP and use different sources of parallel resources (multicomputer, multiprocessor multicore, GPGPU based, or cloud available environment). Our results show that rational usage of hybrid parallelization approach to speed up the critical parts of our code contributes in significant performance improvements [9, 10].

If uniformly compressed thin-walled structures undergo inelastic deformations, these structures generally sustain two sources of non-linearity (geometrical non-linearity due to large deflection and material non-linearity due to inelastic behaviour). Due to the slender nature of the cross-sections, their behaviour is inevitably complex, with several parallel buckling phenomena influencing performance and limit states. The analysis presented in this paper is based on the RDA [11, 12]. The RDA is a type of inelastic analysis, which transforms one category of very complicated material non-linear problems to simpler linear dynamic problems by using modal analysis [13]. In this paper, we present a new approach in which the damages are investigated by RDA to solve the inelastic buckling effective stresses in thin-walled structures. The uniaxial RDA dynamic modulus is based on a concept of a complex modulus of viscoelastoplastic (VEP) materials. This modulus is used to obtain one simple continuous modulus function and a stress-strain curves which were verified with experiments. The key global parameters, such as the creep coefficient, Poisson's ratio and the damage variable, are functionally related [14]. For the analysis of thin-walled structures using the FSM, an inelastic isotropic 2D constitutive matrix is derived starting from the uniaxial state of stress [7]. The damage identification method requires the use 
Contemporary achievements in civil engineering 23-24. April 2019. Subotica, SERBIA

of the FSM to model the structure in its undamaged state as well as information on its dynamic properties when in damaged state. Finally, the effective stress, as defined in the damage mechanics [15], is used.

For the more complex series part of displacement function $Y_{m}$, determined by the end conditions (i.e. both ends clamped), it's not possible to find the exact analytical solution of eigenfunctions [16, 17], due to the hyperbolic sine and cosine functions which are embedded within their characteristic equations. In [18] it's shown that with each increasing mode the characteristic equation root-finding error grows exponentially for any non-trivial edge boundary condition, and once the higher modes have been reached the accuracy is lost. It has also been demonstrated that the said large root-finding errors may lead to severe accuracy issues when computing basis functions and their integrals, especially when higher modes are involved. A hybrid method [18] has been proposed that works around these issues by coupling multiple approaches to minimize the numerical errors throughout the entire computation pipeline.

The idea underlying the approaches presented in this paper is that the influence of mode interactions appears if the dynamic properties in undamaged state as well as in damaged state are used together. The mode interactions have great influence on damage variables and inelastic buckling effective stresses in thin-walled columns.

\section{BUCKLING AND VIBRATION}

\subsection{Buckling}

The non-linear strain-displacement relations in FSM can be predicted by combination of plane elasticity and the Kirchhoff bending plate theory. This has been accomplished in [5], by using the second-order terms of Green-Lagrange strains. However, since longitudinal loading is assumed here (see Fig. 1), the second-order terms are only necessary for the longitudinal normal strain

$$
\varepsilon_{y}=\frac{\partial v_{0}}{\partial y}+\frac{1}{2}\left[\left(\frac{\partial u_{0}}{\partial y}\right)^{2}+\left(\frac{\partial v_{0}}{\partial y}\right)^{2}+\left(\frac{\partial w}{\partial y}\right)^{2}\right]-z \frac{\partial^{2} w}{\partial y^{2}},
$$

where $u_{0}$ and $v_{0}$ are, respectively, displacements in the middle surface in $x$ and $y$ directions, and $w$ is displacement in $z$ direction.

In FSM, which combines elements of the classical Ritz method and the finite element method (FEM), the general form of the displacement function, can be written as a product of polynomials and trigonometric functions

$$
f=\sum_{m=1}^{r} Y_{m}(y) \sum_{k=1}^{c} \mathbf{N}_{k}(x) \mathbf{q}_{k m},
$$

where $Y_{m}(y)$ are functions from the Ritz method, $\mathbf{N}_{k}(x)$ are interpolation functions from FEM [1] and $\mathbf{q}_{k m}$ is a vector representing the $m$-th term nodal displacements. $r$ is an integer specifying the number of series terms chosen for approximation and $c$ represents the number of nodal lines of a strip. 
Савремена достигнућа у грађевинарству 23-24. април 2019. Суботица, СРБИЈА

The most commonly used series are the basis functions which are derived from the solution of the beam vibration differential equation

$$
\frac{d^{4} Y}{d y^{4}}=\frac{\mu^{4}}{a^{4}} Y,
$$

where $a$ is length of beam (strip) and $\mu$ is a parameter [1]. The general solution of Eq.

(3) is

$$
Y(y)=C_{1} \sin \left(\frac{\mu y}{a}\right)+C_{2} \cos \left(\frac{\mu y}{a}\right)+C_{3} \sinh \left(\frac{\mu y}{a}\right)+C_{4} \cosh \left(\frac{\mu y}{a}\right) .
$$

with the coefficients $C_{1}$, etc., to be determined by the boundary conditions. These have been worked out in the ref. [18] for the various boundary conditions but the basis function is listed below for a simply supported strip only

$$
Y_{m}(y)=\sin \left(\frac{\mu_{m} y}{a}\right) \quad\left(\mu_{m}=\pi, 2 \pi, 3 \pi, \ldots m \cdot \pi\right) .
$$

We define the local Degrees Of Freedom (DOFs) as displacements $u_{0}, v_{0}$ and $w$, and the transverse slope amplitude $\varphi=\partial w / \partial x$ of a nodal line (DOFs=4), Fig. 1.

The total potential energy of a strip for plane stress and bending according to the linear theory is designated $\Pi$ and is expressed with respect to the local DOFs [5]

$$
\begin{aligned}
& \Pi=U+W=\left(U^{p}+U^{b}\right)+W=\left(1 / 2 \int_{A} \mathbf{q}_{u}^{T} \mathbf{B}_{u 1}^{T} \mathbf{D}^{p} \mathbf{B}_{u 1} \mathbf{q}_{u} d A+1 / 2 \int_{A} \mathbf{q}_{w}^{T} \mathbf{B}_{w 3}^{T} \mathbf{D}^{b} \mathbf{B}_{w 3} \mathbf{q}_{w} d A\right), \\
& -p_{u} \int_{A} \mathbf{q}_{u}^{T} \mathbf{A}_{u}^{T} d A-p_{w} \int_{A} \mathbf{q}_{w}^{T} \mathbf{A}_{w}^{T} d A
\end{aligned}
$$

where $U$ is the strain energy in which $U^{p}$ is the plane stress energy and $U^{b}$ is the bending energy. The conventional stiffness block matrices are, respectively

$$
\hat{\mathbf{K}}_{u u}=\int_{A} \mathbf{B}_{u 1}^{T} \mathbf{D}^{p} \mathbf{B}_{u 1} d A, \quad \hat{\mathbf{K}}_{w w}=\int_{A} \mathbf{B}_{w 3}^{T} \mathbf{D}^{b} \mathbf{B}_{w 3} d A .
$$

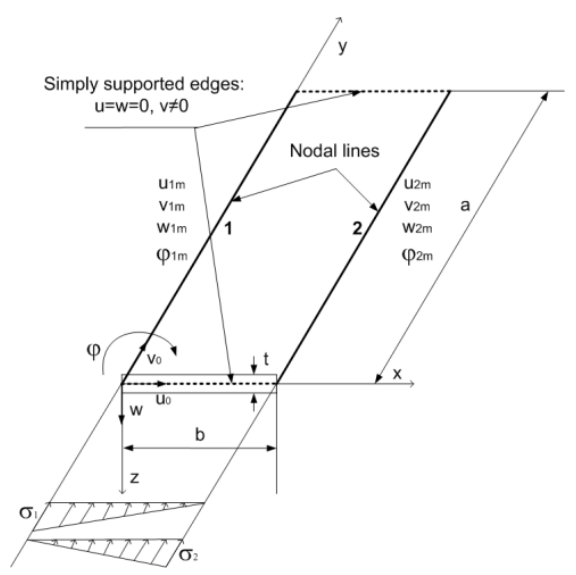

Figure 1: A simple supported rectangular flat shell strip with initial stresses. 
Contemporary achievements in civil engineering 23-24. April 2019. Subotica, SERBIA

We introduce matrices, which are referred to as the strain matrices for the plane stress and bending, respectively

$$
\mathbf{B}_{u 1}=\mathbf{L}_{1} \mathbf{A}_{u}, \quad \mathbf{B}_{w 3}=\mathbf{L}_{3} \mathbf{A}_{w},
$$

where

$$
\mathbf{L}_{1}=\left[\begin{array}{cc}
\partial / \partial x & 0 \\
0 & \partial / \partial y \\
\partial / \partial y & \partial / \partial x
\end{array}\right], \quad \mathbf{L}_{3}=\left[\begin{array}{c}
-\partial^{2} / \partial x^{2} \\
-\partial^{2} / \partial y^{2} \\
-2 \cdot \partial^{2} / \partial x \partial y
\end{array}\right]
$$

Once the approximate functions for the plane stress $\mathbf{A}_{u}$ are known it is possible to define the following matrices and vectors

$$
\mathbf{A}_{u}=\left[\begin{array}{cc}
\mathbf{A}_{u}^{u} & \mathbf{0} \\
\mathbf{0} & \mathbf{A}_{u}^{v}
\end{array}\right], \quad \mathbf{q}_{u}=\left[\begin{array}{c}
\mathbf{q}_{u}^{u} \\
\mathbf{q}_{u}^{v}
\end{array}\right] .
$$

Hence, $\mathbf{A}_{u}^{u}, \quad \mathbf{A}_{u}^{v}$ and $\mathbf{A}_{w}$ are the corresponding approximate functions for displacements $u_{0}, v_{0}$ and $w$ in the middle surface, respectively, while $\mathbf{q}_{u}^{u}, \mathbf{q}_{u}^{v}$ and $\mathbf{q}_{w}$ represent vectors of displacement parameters in the nodal lines.

The potential energy due to external surface loads $p_{u}$ and $p_{w}$ can be written simply as

$$
W=-p_{u} \int_{A} \mathbf{q}_{u}^{T} \mathbf{A}_{u}^{T} d A-p_{w} \int_{A} \mathbf{q}_{w}^{T} \mathbf{A}_{w}^{T} d A=-\mathbf{q}_{u}^{T} \mathbf{Q}_{u}-\mathbf{q}_{w}^{T} \mathbf{Q}_{w} .
$$

In order to obtain the equilibrium equations, the principle of minimum total potential energy is invoked

$$
\frac{\partial \Pi}{\partial \mathbf{q}_{u m}^{T}}=\mathbf{0}, \quad \frac{\partial \Pi}{\partial \mathbf{q}_{w m}^{T}}=\mathbf{0} .
$$

in which $\mathbf{q}_{u m}^{T}$ and $\mathbf{q}_{w m}^{T}$ are vectors for the $m$ th term of the series. Eq. (12) gives a linear set of algebraic equations. Because of orthogonal property of functions $Y_{m}$, Eq. (5) the algebraic equations take up the form where all the series are uncoupled

$$
\left[\begin{array}{cc}
\hat{\mathbf{K}}_{u u m m} & \mathbf{0} \\
\mathbf{0} & \hat{\mathbf{K}}_{w w m m}
\end{array}\right]\left[\begin{array}{l}
\mathbf{q}_{u m} \\
\mathbf{q}_{w m}
\end{array}\right]=\left[\begin{array}{c}
\mathbf{Q}_{u m} \\
\mathbf{Q}_{w m}
\end{array}\right] .
$$

Well known elements of the property matrices $\mathbf{D}^{p}$ and $\mathbf{D}^{b}$ for the plane stress and bending, respectively, for the orthotropic elastic material are 
Савремена достигнућа у грађевинарству 23-24. април 2019. Суботица, СРБИЈА

$$
\begin{aligned}
& K_{x}=\frac{E_{x}}{1-\mu_{x} \mu_{y}}, K_{y}=\frac{E_{y}}{1-\mu_{x} \mu_{y}}, K_{1}=\frac{\mu_{y} E_{x}}{1-\mu_{x} \mu_{y}}=\frac{\mu_{x} E_{y}}{1-\mu_{x} \mu_{y}}, K_{x y}=G \\
& D_{11}^{p}=K_{x} t, D_{22}^{p}=K_{y} t, D_{12}^{p}=K_{1} t, D_{66}^{p}=K_{x y} t \\
& D_{11}^{b}=K_{x} \frac{t^{3}}{12}, D_{22}^{b}=K_{y} \frac{t^{3}}{12}, D_{12}^{b}=K_{1} \frac{t^{3}}{12}, D_{66}^{b}=K_{x y} \frac{t^{3}}{12}
\end{aligned}
$$

In the above expressions, $E_{x}, E_{y}, \mu_{x}, \mu_{y}$, and $G$ are the elastic constants while $t$ is the thickness of the strip, Fig. 1.

Consider the simply supported flat shell strip. The strip is subjected to an initial stress $\sigma_{y}$, which varies linearly from side 1 to side 2 as shown in Fig. 1, but is constant along the longitudinal axis

$$
\sigma_{y}=\left(1-\frac{x}{b}\right) \sigma_{1}+\frac{x}{b} \sigma_{2}
$$

Considering the assigned stress distribution, from the non-linear strain tensor we include only the term given by Eq. (1). The total potential energy of a strip is defined as the sum of its strain energy, potential energy due to nodal line forces, as well as the additional potential energy due to the initial stresses. As far as linear stability is concerned, the nodal forces $\mathbf{Q}$ are zero and it's therefore possible to derive the eigenvalue equation [5]

$$
\left(\hat{\mathbf{K}}-\lambda \mathbf{K}_{\sigma}\right) \mathbf{b}=\mathbf{0},
$$

where $\hat{\mathbf{K}}=\left[\begin{array}{cc}\hat{\mathbf{K}}_{u u} & \mathbf{0} \\ \mathbf{0} & \hat{\mathbf{K}}_{w w}\end{array}\right] . \mathbf{K}_{\sigma}$ is the corresponding geometric stiffness matrix [7], $\lambda$ is the eigenvalue (the load factor is compression positive), and $\mathbf{b}$ is the eigenvector (buckling mode). Based on Eq. (16) for one finite strip we can form the eigenvalue equations for a system of finite strips (mesh). The eigenvalue problem is to extract the solution pairs $\lambda_{\text {im }}$ and $\mathbf{b}_{\text {im }}$ for all DOFs $i$, and all series terms $m=1, \ldots r$. The buckling stresses can then be obtained as follows

$$
\sigma_{i m}=\frac{\lambda_{i m}}{2 \cdot t} .
$$

\subsection{Vibration}

The stability and instability of a static equilibrium state are conventionally defined in terms of free motions of the system following an infinitesimal and once-and-for-all disturbance from the equilibrium state. The linear equations of free vibration in the matrix form are as follows [5]

$$
\mathbf{M} \ddot{\mathbf{q}}+\hat{\mathbf{K}} \mathbf{q}=\mathbf{0}
$$




\section{$7^{\text {th }}$}

Contemporary achievements in civil engineering 23-24. April 2019. Subotica, SERBIA

$\mathbf{M}$ is the mass matrix and $\ddot{\mathbf{q}}$ are accelerations in the nodal lines of a finite strip. We consider natural frequencies of vibration under an assumption that each DOF executes harmonic motion in phase with all other DOFs. Therefore

$$
\mathbf{q}=\boldsymbol{\Phi} e^{i \omega t}, \quad e^{i \omega t}=\cos \omega t+i \sin \omega t .
$$

Matrix Eq. (18) is now

$$
(\hat{\mathbf{K}}-\lambda \mathbf{M}) \boldsymbol{\Phi}=\mathbf{0} .
$$

This is the basic statement of the vibration problem. If there is neither geometric nor material non-linearity, then neither $\hat{\mathbf{K}}$ nor $\mathbf{M}$ are a function of $\omega$, and Eq. (20) is a standard eigenvalue problem. For a mesh of finite strips we obtain

$$
\lambda_{i m}=\omega_{i m}^{2}, \text { and } \boldsymbol{\Phi}_{i m},
$$

where $\omega_{i m}$ are the natural frequencies. For each $\omega_{i m}$ there is a corresponding vibration eigenvector $\boldsymbol{\Phi}_{i m}$.

We find it very important, to point out that a duality exists between the free vibration and buckling under a uniform end compression, where the eigenvectors are identical. Thus, corresponding eigenvalues for a mesh of finite strips are related by

$$
\omega_{i m}^{2}=\frac{\sigma_{i m}}{\rho}\left(\frac{m \pi}{a}\right)^{2},
$$

where $\rho$ is the mass density.

\section{VIBRATION AND INELASTIC BUCKLING USING THE RDA}

\subsection{RDA - a short overview}

This section can be thought of as an extension to Section 2.2. The purpose of developing a mathematical model for the rheological behaviour of solids is to permit realistic results to be obtained from mathematical analyses of damaged structures under various conditions, such as sinusoidal loading $Q(t)=Q_{A} \sin \left(\omega_{Q} t\right)$ with amplitude $Q_{A}$ and circular frequency $\omega_{Q}$, Fig. 2 . 


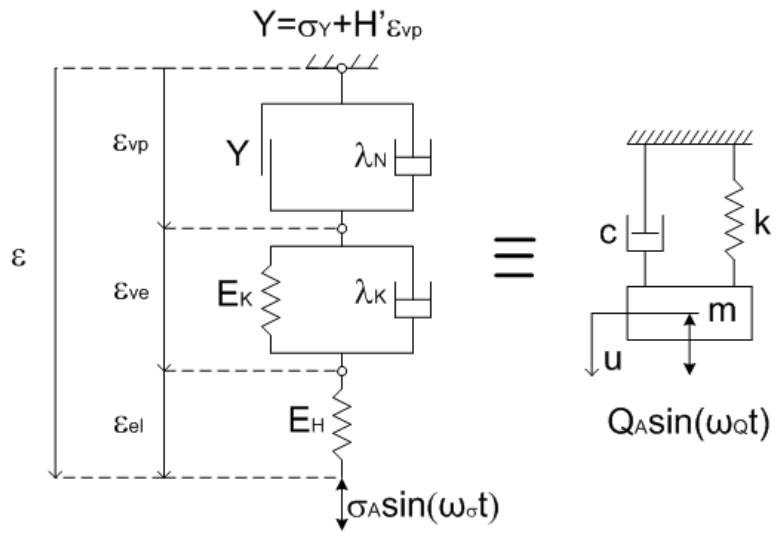

Figure 2: Rheological-dynamical analogy.

The governing differential equation between strain and stress that includes their first and second time derivatives has already been derived by the first author of this paper in [13]

$$
m \frac{d^{2} \varepsilon}{d t^{2}}+c \frac{d \varepsilon}{d t}+k \varepsilon=\tilde{m} \frac{d^{2} \sigma}{d t^{2}}+\tilde{c} \frac{d \sigma}{d t}+\tilde{k} \sigma-\tilde{k}^{*} \sigma_{Y} .
$$

According to the basic RDA equations, the mass and stiffness are respectively $m=\lambda_{K} \lambda_{N} / \gamma, k=E_{K} H^{\prime} / \gamma$. The viscous damping is $c=\left(E_{K} \lambda_{N}+H^{\prime} \lambda_{K}\right) / \gamma$. The four properties at fixed step times are the extensional viscoelastic (VE) viscosity $\lambda_{K}$, the extensional viscoplastic (VP) viscosity $\lambda_{N}$, the VE modulus $E_{K}$, and the VP modulus $H^{\prime} . \gamma=\rho g$ is the specific gravity, $E_{H}$ the Young's modulus, $\sigma_{Y}$ the uniaxial yield stress, and $Y=\sigma_{Y}+H^{\prime} \varepsilon_{v p}$ the yield condition. $\varepsilon_{v p}$ is the VP irreversible strain. Critical damping under condition $E_{K} / \lambda_{K}=H^{\prime} / \lambda_{N}$, [11] is a particular value of damping coefficient $\xi=c / c_{c r}$ (the minimum one) that determines the return to equilibrium condition of a system without oscillations. Hence

$$
\begin{aligned}
& m=\lambda_{K} \lambda_{N} / \gamma=k T^{D 2}, \quad c=\left(E_{K} \lambda_{N}+H^{\prime} \lambda_{K}\right) / \gamma=2 \cdot k T^{D}, \\
& \tilde{m}=\left(1 / E_{H}\right) k T^{D 2}, \quad \tilde{c}=\left(1 / E_{H}\right) k(2+\varphi) T^{D}, \\
& \tilde{k}=\left(1 / E_{H}\right) k(1+\varphi), \quad \tilde{k}^{*}=\left(1 / E_{H}\right) k\left(\varphi-\varphi^{*}\right),
\end{aligned}
$$

where $\varphi^{*}$ and $\varphi$ are the VE and VEP creep coefficients, respectively. Consequently, the key result from the RDA complementary solution is the following relation between natural frequency and delay time $T^{D},[11]$

$$
\omega=1 / T^{D} .
$$


Contemporary achievements in civil engineering 23-24. April 2019. Subotica, SERBIA

Also, the RDA asks for a steady-state response to the sinusoidal varying stresses

$$
\sigma(t)=\sigma_{0}+\sigma_{A} \sin \left(\omega_{\sigma} t\right)
$$

with $\sigma_{0}$ being a constant and $\sigma_{A}$ a variable component of the cycle. $\omega_{\sigma}$ is the stress frequency, $\omega_{Q}=\omega_{\sigma}$. Such stressing conditions have come to be known in rheology as dynamic loading and are used in the analysis of the fatigue behaviour [11]. In accordance with RDA, the fatigue strength under constant stress amplitude is

$$
\sigma_{e}(R)=\left(\frac{1}{2}\right) \sigma_{\max }\left[1+R+(1-R) \sqrt{\frac{(1+\varphi)^{2}+\delta^{2}}{1+\delta^{2}}} \frac{1}{1+\varphi}\right]
$$

where $R=\sigma_{\min } / \sigma_{\max }$ is the ratio of minimum stress to maximum with the signs taken into account. $\delta=\omega_{Q} / \omega=T^{D} \omega_{Q}$ is the relative frequency.

An approach based on energy considerations, which includes the rate of release of VEP energy, has already been adopted in the RDA theory. The VEP energy release rate is derived in [11] as follows

$$
W_{d, v e}(R)=2 \cdot \pi \cdot k\left(\frac{\sigma_{\max }}{E_{H}}\right)^{2} \frac{(1-R)^{2}}{4} \frac{(1+\varphi)^{2}+\delta^{2}}{1+\delta^{2}} \delta
$$

According to the damage mechanics [22], the damage variable $D$ may be characterized by the variation in Young's modulus $E(D)$. Under an assumption that variation from undamaged to the damaged state is equal to the RDA dynamic modulus, $E(D)=(1-$ $D) E_{H}=E_{R}$, the damage variable was obtained from the creep coefficient and relative frequency in [14] as follows

$$
D=\frac{(1+\varphi) \varphi}{(1+\varphi)^{2}+\delta^{2}}
$$

Hence, the dependence between the damage variable and its associated VEP energy release rate determines the evolution of the damage according to the RDA, Fig. 3. 


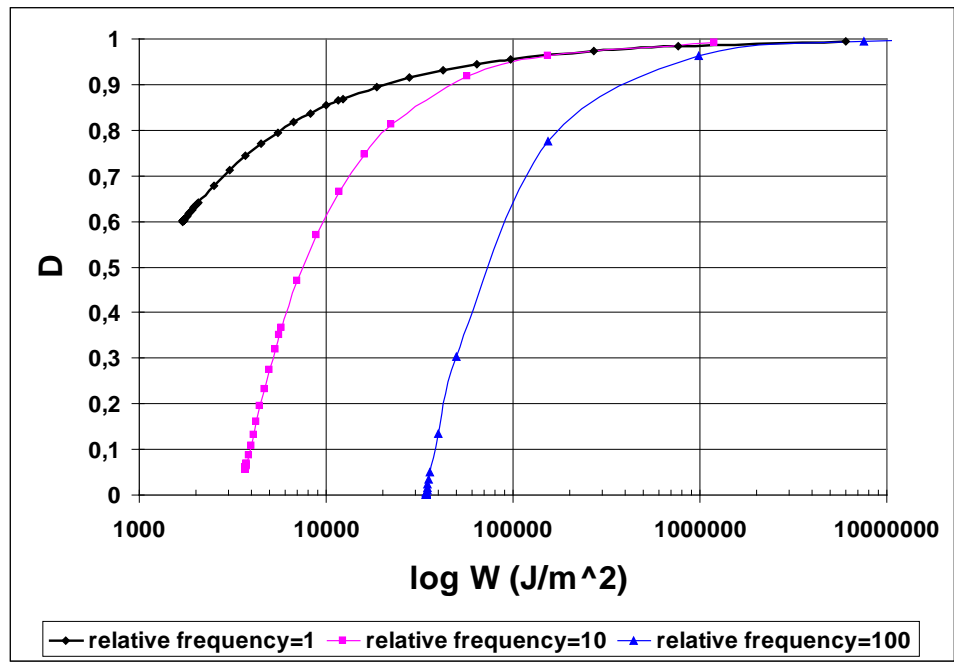

Figure 3: Dependence of the damage variable on the VEP energy release rate [ $\left.\mathrm{J} / \mathrm{m}^{2}\right]$ for different values of relative frequency for the reinforced steel rod in symmetrical cycle

$$
(R=-1)[11] \text {. }
$$

In this paper, the damage variable $0<=D<=1$ under the quasi-static loading $(\delta \rightarrow 0)$ is used that was experimentally proved in [14]

$$
\underset{\lim \delta \rightarrow 0}{D}=\frac{\varphi}{1+\varphi} .
$$

The assumption of isotropic damage is often sufficient to give a good prediction of the carrying capacity, the number of cycles or the time to local failure in structural components [22].

\subsection{Effective stress}

According to interpretations in the rheology, the viscoelastic Poison ratio is defined in a time or frequency domain [19]. Since it is a dimensionless value that grows in a defined domain to a defined boundary of incompressibility, it is associated with an increase in material damage. A similar property has a creep coefficient, which is also a dimensionless value and can be interpreted as a variable of damage. The RDA approach, which considers both the initial (undamaged) and damaged (viscoelastic) state of cylindrical rod for the analysis of the influence of Poisson ratio on the creep coefficient, has already been described by the first author in [11].

The energy equation results from application of the principle of conservation of energy to steady transfer of energy,

$$
\sigma_{1}+\frac{1}{2} \rho v_{1}^{2}=\sigma_{2}+\frac{1}{2} \rho v_{2}^{2}=\sigma_{2}+\frac{1}{2} \rho\left(\frac{A_{1}}{A_{2}}\right)^{2} v_{1}^{2}
$$


Contemporary achievements in civil engineering 23-24. April 2019. Subotica, SERBIA

where the equation of continuity, which results from the principle of conservation of mass is used, Fig. 4

$$
A_{1} v_{1}=A_{2} v_{2} \Rightarrow A_{2}=A_{1}\left(v_{1} / v_{2}\right)
$$

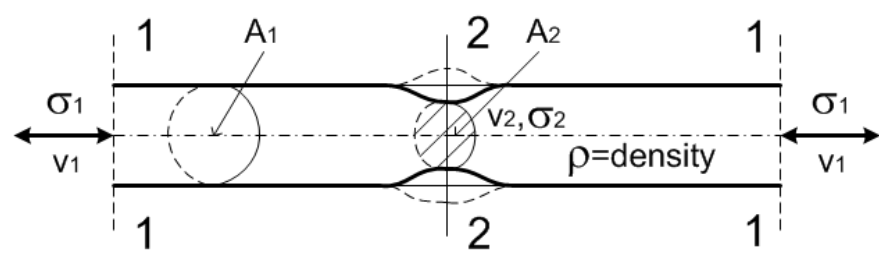

Figure 4: Steady transfer of energy through a long rod.

$v_{1}=\sqrt{E_{H} / \rho}$ is the phase velocity of mechanical wave, and $\sigma_{2}=\sigma_{e}$ is the RDA fatigue limit ( $\delta \rightarrow 100$ ) in symmetrical cycle $(R=-1)$. For the critical stress at the limit of elasticity $\sigma_{1}=\sigma_{\max }=\sigma_{E}$, Eq. (27) gives

$$
\sigma_{2}=\underset{\lim \delta \rightarrow 100}{\sigma_{e}(-1)}=\frac{\sigma_{\max }}{1+\varphi}=\frac{\sigma_{E}}{1+\varphi} .
$$

In this approach, based on Bernoulli's energy theorem and assuming that $\varepsilon_{E}=\sigma_{E} / E_{H}$ $=0.001$, the creep coefficient is expressed by the formula [11]

$$
\varphi(\mu)=\left[\left(\frac{1}{1-0.001 \mu}\right)^{4}-1\right] \frac{1}{2 \cdot 0.001} /\left\{1-\left[\left(\frac{1}{1-0.001 \mu}\right)^{4}-1\right] \frac{1}{2 \cdot 0.001}\right\} .
$$

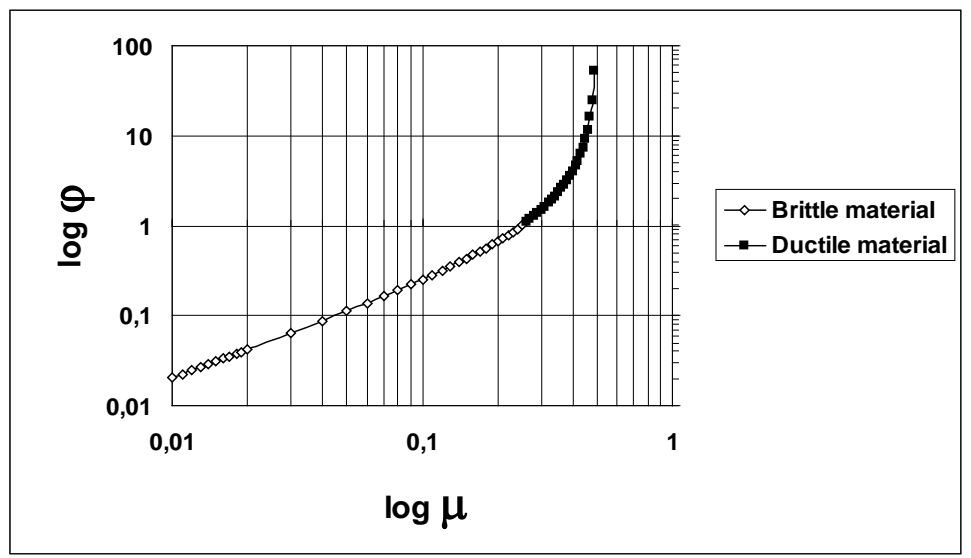

Figure 5: Variation of the creep coefficient with Poisson ratio. 
Fig. 5 presents a relation whose results are in agreement with the experimentally obtained values. Experiments with ductile mild steel show that the measured value of Poisson ratio corresponds to the instantaneous value of $1 / 3$. An axial fatigue experiment was performed on an isolated reinforced steel $\operatorname{rod}, l_{0}=50 \mathrm{~cm}, \Phi=1.9 \mathrm{~cm}$ [11]. $\varepsilon_{E}=0.000891$ is the measured value of elastic strain. It has been proved that the limit of elasticity of ductile mild steel is in good accordance with the slenderness ratio of $l_{0} / i=105.26$, where radius of gyration is $i=\sqrt{I / A_{0}}=\Phi / 4=0.475 \mathrm{~cm}$. The critical stress at the limit of elasticity of the two-hinged rod is defined by Euler's formula $\sigma_{E}=\pi^{2} E_{H} /\left(l_{0} / i\right)^{2}=187 \mathrm{MPa}$, where $E_{H}=210000 \mathrm{MPa}$.

A semi-brittle material is determined by the linear dependence of $\log \varphi$ on $\log \mu$. As it is shown in Fig. 5, according to the criterion of the linear logarithm $\varphi-\mu$ dependence, the upper boundary value of Poisson ratio is 0.25 . However, assuming a value of $\mu$ equal to $1 / 3$ for ductile mild steel, we obtain $\varphi=2$.

Eq. (34) can be simplified by neglecting the products of second-order exponents,

$$
\left[\left(\frac{1}{1-0.001 \mu}\right)^{4}-1\right] \frac{1}{2 \cdot 0.001}=\frac{2 \mu}{1-0.004 \mu} \approx 2 \mu \text {. }
$$

Hence, the mathematical expression for obtaining the value of the creep coefficient from the viscoelastic Poisson ratio is given by

$$
\varphi=\frac{2 \mu}{1-2 \mu} .
$$

Poisson ratio, as defined in an idealized purely elastic material, is an elastic constant. However, such a material is hypothetical because it does not exist in the strict sense of the word. In any mechanical deformation the deformation energy is not only stored elastically, but part of it is invariably dissipated by viscous forces, in accordance with the second law of thermodynamics. This dissipation is responsible for the time dependence of the mechanical properties of any real material. Hence, the viscoelastic Poisson ratio in time domain chosen can be defined as follows [19]

$$
\mu(t)=\mu_{e}-\left(\mu_{e}-\mu_{g}\right) e^{-\frac{t}{T^{D}}}
$$

where $\mu_{e}=0.5$ and $\mu_{g}=1 / 3$ are the equilibrium and instantaneous Poisson ratios, respectively. From this, RDA approach includes the creep coefficient as function of time via Poisson ratio.

The dynamic modulus $E_{R}$ is based on the concept of the complex modulus [11, 12] as time dependent property of a material

$$
E_{R}=E_{H} \frac{1+\varphi+\delta^{2}}{(1+\varphi)^{2}+\delta^{2}}, \underset{\lim \delta \rightarrow 0}{E_{R}}=E_{H} \frac{1}{1+\varphi} .
$$


Contemporary achievements in civil engineering 23-24. April 2019. Subotica, SERBIA

Consequently, in order to solve the viscoelastic problem of structures, the dynamic modulus must be used in the conventional stiffness matrix $\hat{\mathbf{K}}$ of a finite strip.

Bifurcation problem given by Eq. (16) belongs to the scope of linear analysis, and determination of critical load reduces to solution of eigenvalue problem. Beside that, Eq. (20) can be used to determine the natural frequencies and mode shapes of a structure, and it forms the basis for many damage detection methods that make use of modal properties in damage detection and identification [20]. The residual force is given as follows [21]

$$
\mathrm{R}=-k+\left(\omega^{d}\right)^{2} m=k\left(1-\left(\frac{\omega^{d}}{\omega}\right)^{2}\right)
$$

where $k$, and $m$ are, respectively, the stiffness and mass of the undamaged column. $\omega^{d}$ is the natural frequency, which must be obtained from the viscoelastic eigenvalue problem. Hence, the damage variable used in the paper in the point of bifurcation is obtained from the natural frequencies as follows

$$
\mathrm{D}=\frac{-R}{k}=1-\left(\frac{\omega^{d}}{\omega}\right)^{2} .
$$

Finally, the effective buckling stress is given using the damage mechanics [22]

$$
\tilde{\sigma}=\frac{\sigma^{d}}{1-D}=\sigma^{d}\left(\frac{\omega}{\omega^{d}}\right)^{2}
$$

where $\sigma^{d}$ is the inelastic buckling stress of damaged structure, which can be obtained either from viscoelastic eigenvalue problem, or from duality, Eq. (22).

\section{FINITE STRIP COMPUTER MODELLING}

\subsection{Finite strip software for inelastic eigenvalue problem (MKTB)}

The finite strip modelling software is composed of two loosely-coupled software modules (Fig. 6). The MKTB module is in charge of inelastic eigenvalue problem computation. It produces extensive quantity of numeric results that cannot be comprehended without an appropriate visualisation module. 


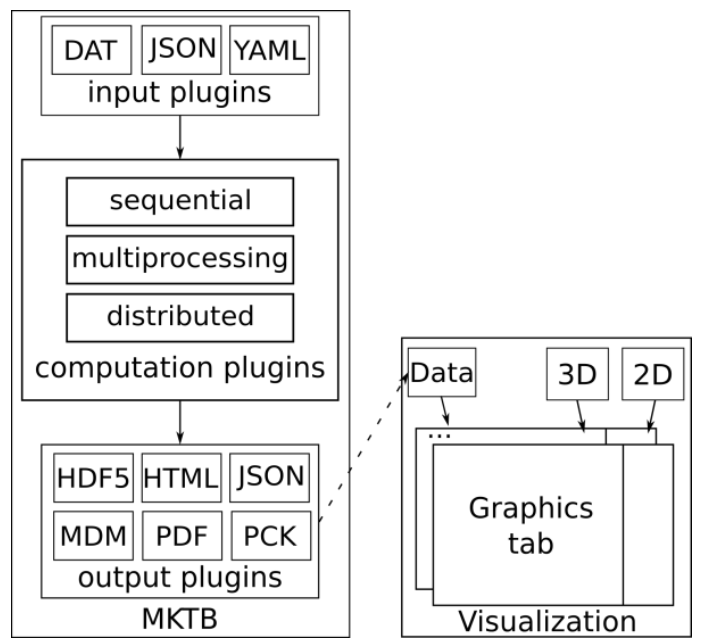

Figure 6: Overall software architecture.

\subsection{Finite strip modelling supported by data visualisation}

As the amount of output data from the MKTB module is overwhelming, to be able to look at required aspects of it, some aggregate representation is needed, and one of best ways to do it is to use visualisation. Depending of the wanted analysis, parts of the data need to be filtered by some criteria and displayed as 2D or 3D graph, or as multiple graphs on the same picture. For example, displaying 3D model of the beam requires extracting initial cross section layout and displacement data for each strip, all that for selected length and mode. Other types of graphs require, for example, extracting specific data for all available lengths and/or modes.

It must be noted that our research requires almost constant adjustments and additions to data visualisation. To be able to respond quickly, our visualisation software needs to be flexible enough for on-demand adjustments to existing graphs, quick additions and adjustments of graph modification parameters, and a way to quickly expand it with new types of graphs.

Visualisation is based on Qt framework and Python classes that are designed for rapid non-visual GUI development, making adding or removing elements a matter of one or few lines of code. The main window of visualisation software is divided into tabs, each representing a different view of the data. Every tab has two main parts, one larger that holds the graphics, and one smaller that contains numerous options for graphics customization (Fig. 7). Two helper classes for graphics representation are developed, currently both based on matplotlib (the actual back-end can be replaced relatively easily), one for 2D and one for 3D graphics.

Adding a new graph type to the program consists of deriving a new class from main tab class, overriding of its plot method, to describe new data representation, and adding object of that class to the application window. Main tab class defines the main tab appearance (graphics part and options part), and has numerous methods for dynamic 
Contemporary achievements in civil engineering 23-24. April 2019. Subotica, SERBIA

addition of attributes and methods for their handling to the derived class. For example, if there needs to be an element to choose some values forms combo-box, all one needs to do is to call addLabelComboBox method which will dynamically add several attributes and methods to the derived tab class:

- a label with text "File" to the options panel, followed by combo-box

- $\quad$ an attribute that will hold data for currently selected string from combo-box

- an attribute that will hold currently selected string from combo-box

- $\quad$ an attribute that will hold all the Qt graphical elements that are added

- a helper function that can be used to set what strings should be included as options for combo-box, and what optional data should be associated with each string (by default, data is the same as string)

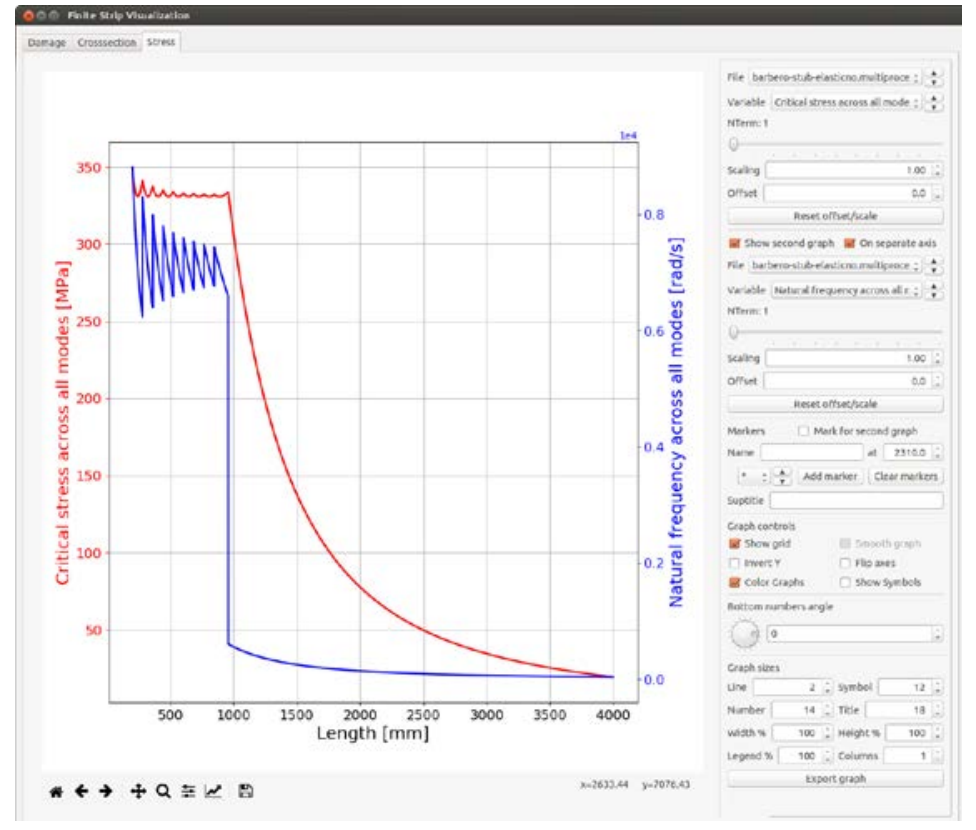

Figure 7: Graphics customization.

All of the mentioned attributes and methods are available in derived tab class immediately after the call of addLabelComboBox. By default, after each change of the selected item, there will be a call to tab's update method, that in turn calls plot method. That way, there is no need for explicit update of the graphics display. Of course, custom callback functions can be defined for each element. Optional sync parameter for each added element can be used to synchronize its value with elements from other tabs that have the same name. This can be used, for example, to synchronize selected file on multiple tabs, so that each of the tabs will show its data based on the same source. The same traits described for combo-box are available for the rest of elements that can be added to options panel (radio and check buttons, numbers, text fields, sliders, etc.) making defining new tabs a relatively automated process. 
Савремена достигнућа у грађевинарству 23-24. април 2019. Суботица, СРБИЈА

\subsection{Numerical applications}

In this paper the simply supported ideally straight thin-walled wide-flange $\mathrm{H}$-section column is analyzed. The column of length $a=2310 \mathrm{~mm}$ consists of a web and two flanges of side $b=152 \mathrm{~mm}$ [23]. The thickness $t$ is $6.35 \mathrm{~mm}$. The column is compressed axially. The bending stiffness $E I=89.6 \mathrm{kNm}^{2}$ about the weak axis of the analysed column was computed from the information provided by the manufacturer for each section following the methodology developed by Barbero and Tomblin [24]. This information includes the type of fibres and matrix material, the local orientation of the fibres and the fibre content in the cross-section. Tab. 2 shows the flange and web bending stiffness components for $152 \mathrm{~mm}$ x $152 \mathrm{~mm}$ x $6.35 \mathrm{~mm}$ pultruded WF H-section column.

Table 2: Weak axis bending stiffness components of flanges and web: test data [23]

\begin{tabular}{|c|c|c|c|c|}
\hline & $\mathrm{b}=152 \mathrm{~mm}$ & Stiffness component (kNm) & Flanges & Web \\
\hline $\begin{array}{c}\Omega \\
t=6.35\end{array}$ & \begin{tabular}{|l}
$\mathrm{b}_{\mathrm{w}}=142.5$ \\
$\mathrm{t}_{\downarrow} \quad \mathrm{x}$
\end{tabular} & $\begin{array}{l}D_{11} \\
D_{22} \\
D_{12} \\
D_{66}\end{array}$ & $\begin{array}{c}302.95 \\
116.28 \\
44.35 \\
38.52\end{array}$ & $\begin{array}{l}0.46217 \\
0.21052 \\
0.08267 \\
0.06736\end{array}$ \\
\hline
\end{tabular}

The material properties in Table 3 for the implementation of HCFSM are obtained as detailed in [7]. These material parameters are also used for the FSM eigenvalue computations within this paper.

Table 3: Material properties of flanges and web

\begin{tabular}{|l|c|c|c|c|}
\hline \multirow{2}{*}{$\begin{array}{l}\text { Material } \\
\text { Properties } \\
\left(\mathrm{N} / \mathrm{mm}^{2}\right)\end{array}$} & \multicolumn{2}{|c|}{ Elastic } & Viscoelastic \\
\cline { 2 - 5 } & Flanges & Web & Flanges & Web \\
\hline$E_{x}$ & 62786.25 & 52906.25 & 20928.75 & 17635.42 \\
\hline$E_{y}$ & 24098.98 & 24098.98 & 8032.99 & 8032.99 \\
\hline$\mu_{x}$ & 0.38 & 0.39 & 0.38 & 0.39 \\
\hline$\mu_{y}$ & 0.15 & 0.18 & 0.15 & 0.18 \\
\hline$G$ & 1805287.39 & 3156.91 & 1805287.39 & 3156.91 \\
\hline
\end{tabular}

The buckling behaviour of ideally straight column to axial loading and small transverse concentrated load has already been investigated by the HCFSM [7]. Milašinović [5] developed a harmonic coupled FSM by including the Green-Lagrange strain terms in the formulations, thus bending and membrane are coupled in the geometric stiffness to give more accurate buckling behaviour prediction, especially in large-deflection and elastic 


\section{$7^{\text {th }}$}

Contemporary achievements in civil engineering 23-24. April 2019. Subotica, SERBIA

post-buckling analysis. The following approximate functions are used for the simply flat shell strip

$$
\begin{aligned}
& u_{0}=\mathbf{A}_{u}^{u} \mathbf{q}_{u}^{u}=\sum_{m=1}^{r} Y_{u m}^{u} \mathbf{N}_{u}^{u} \mathbf{q}_{u m}^{u}=\sum_{m=1}^{r} Y_{u m}^{u}[1-x / b \quad x / b] \mathbf{q}_{u m}^{u}, \\
& v_{0}=\mathbf{A}_{u}^{v} \mathbf{q}_{u}^{v}=\sum_{m=1}^{r} \frac{a}{m \pi} Y_{u m}^{v} \mathbf{N}_{u}^{v} \mathbf{q}_{u m}^{v}=\sum_{m=1}^{r} \frac{a}{m \pi} Y_{u m}^{v}\left[\begin{array}{ll}
1-x / b & x / b
\end{array}\right] \mathbf{q}_{u m}^{v}, \\
& w=\mathbf{A}_{w} \mathbf{q}_{w}=\sum_{m=1}^{r} Y_{w m} \mathbf{N}_{w} \mathbf{q}_{w m}=\sum_{m=1}^{r} Y_{w m}\left[\begin{array}{llll}
N_{1} & N_{2} & N_{3} & N_{4}
\end{array}\right] \mathbf{q}_{w m}, \\
& N_{1}(x)=1-3(x / b)^{2}+2(x / b)^{3}, \quad N_{2}(x)=b\left[x / b-2(x / b)^{2}+(x / b)^{3}\right] \text {, } \\
& N_{3}(x)=3(x / b)^{2}-2(x / b)^{3}, \quad N_{4}(x)=b\left[-(x / b)^{2}+(x / b)^{3}\right] \text {, } \\
& Y_{u m}^{u}(y)=\sin (m \pi y / a)=Y_{w m}(y), \\
& Y_{u m}^{v}(y)=d Y_{u m}^{u} / d y=(m \pi / a) \cos (m \pi y / a), \quad m=1,2,3, \ldots
\end{aligned}
$$

The interaction between the modes, shown in Fig. 8, is analysed taking into account the governing dynamic RDA modulus along the longitudinal axis. The HCFSM algorithm for geometric non-linear analysis has been described in [9] and [10].

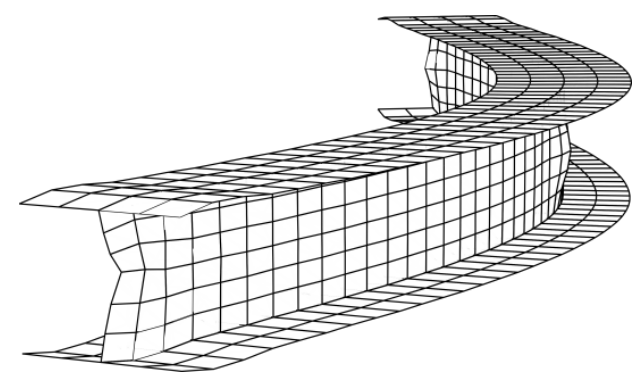

Figure 8: Buckling behaviour of simply supported ideally straight composite thin-walled $H$-section column to axial loading by the HCFSM.

The semi-analytical FSM eigenvalue analysis of a structure is simpler as it is explained in Section 4.1. H-section column is divided into 14 finite strips with 15 nodal lines. The main role has eigenvalues and corresponding eigenvectors. Fig. 9 presents first four local eigenvectors on length of $200 \mathrm{~mm}$, respectively, while Fig. 10 presents first four global eigenvectors on length of $2310 \mathrm{~mm}$. Though elastic buckling information for thin-walled members is not a direct predictor of capacity or collapse behaviour on its own, both the mode and the load are important proxies for the actual behaviour. In current design codes, such as AISI S100, New Zealand/Australia, and European Union, the design formulae are calibrated through the calculation of elastic critical buckling loads to 
Савремена достигнућа у грађевинарству 23-24. април 2019. Суботица, СРБИЈА

predict the ultimate strength, thus the ability to calculate the associated elastic buckling loads is of great importance. Moreover, the buckling mode shapes are commonly employed into non-linear collapse modelling as initial geometric imperfections.

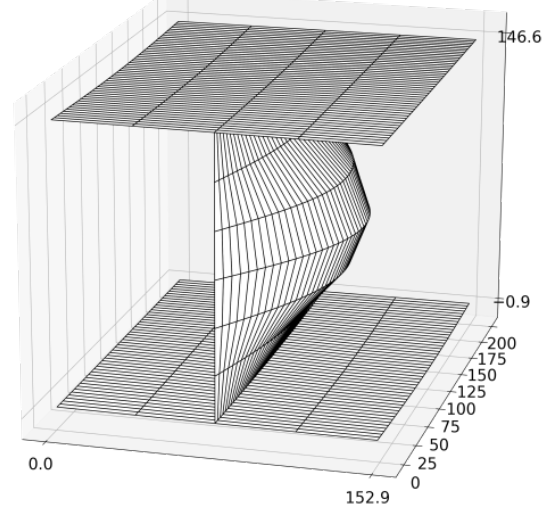

Length $200.0 \mathrm{~mm}$, Modal vector 1, Scaling 4000

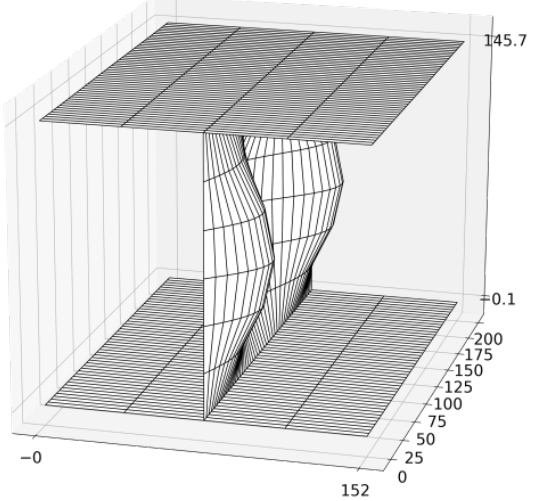

Length 200.0mm, Modal vector 3, Scaling 4000

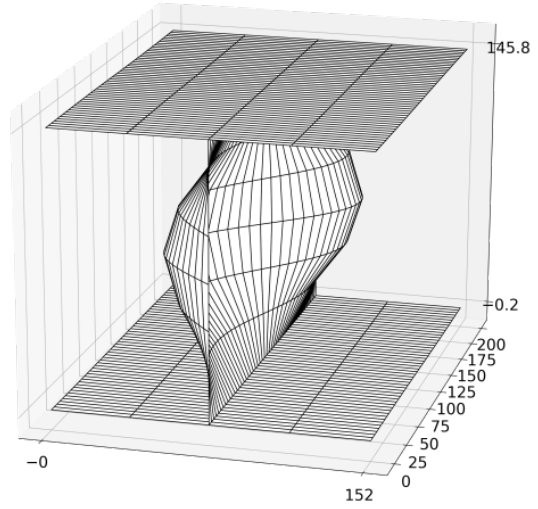

Length $200.0 \mathrm{~mm}$, Modal vector 2, Scaling 4000

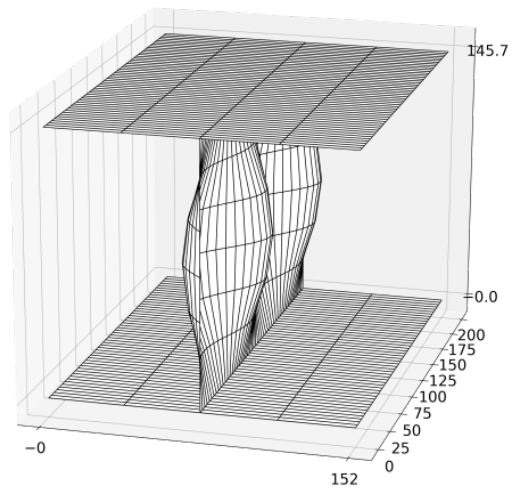

Length $200.0 \mathrm{~mm}$, Modal vector 4 , Scaling 4000

Figure 9: First four local eigenvectors on length of $200 \mathrm{~mm}$. 


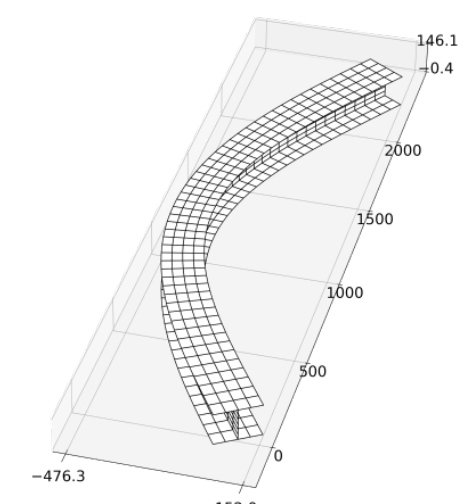

Length $2310.0 \mathrm{~mm}$, Modal vector 1, Scaling 9000

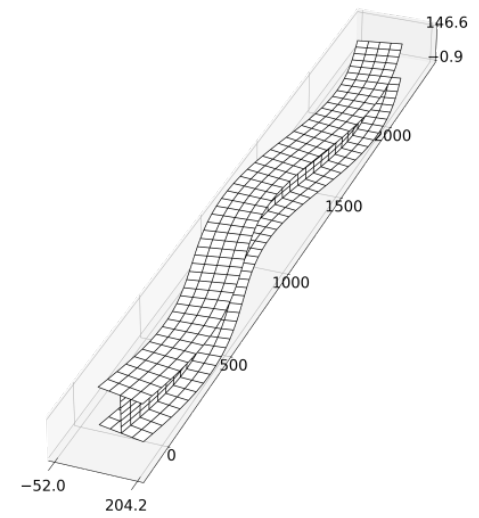

Length 2310.0mm, Modal vector 3, Scaling 9000

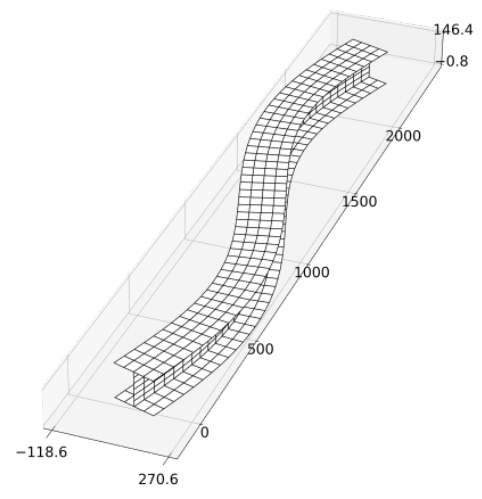

Length $2310.0 \mathrm{~mm}$, Modal vector 2, Scaling 9000

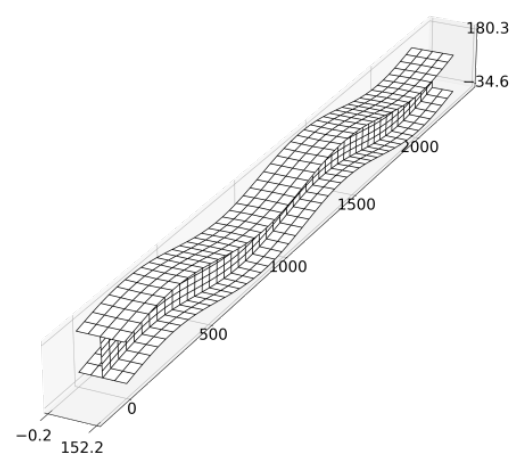

Length 2310.0mm, Modal vector 4, Scaling 9000

Figure 10: First four global eigenvectors on length of $2310 \mathrm{~mm}$.

Fig. 11 shows the results of critical buckling stresses for the elastic and viscoelastic solutions of the problem, by the procedure explained in Section 2.1. The column length has been successively increased from 200 to $4000 \mathrm{~mm}$, with a step of $0.5 \mathrm{~mm}$.

The obtained buckling curves have discontinuities in short intervals of lengths and intersection of modes at the end of those intervals. With each increasing mode, the elastic discontinuities are getting wider. 


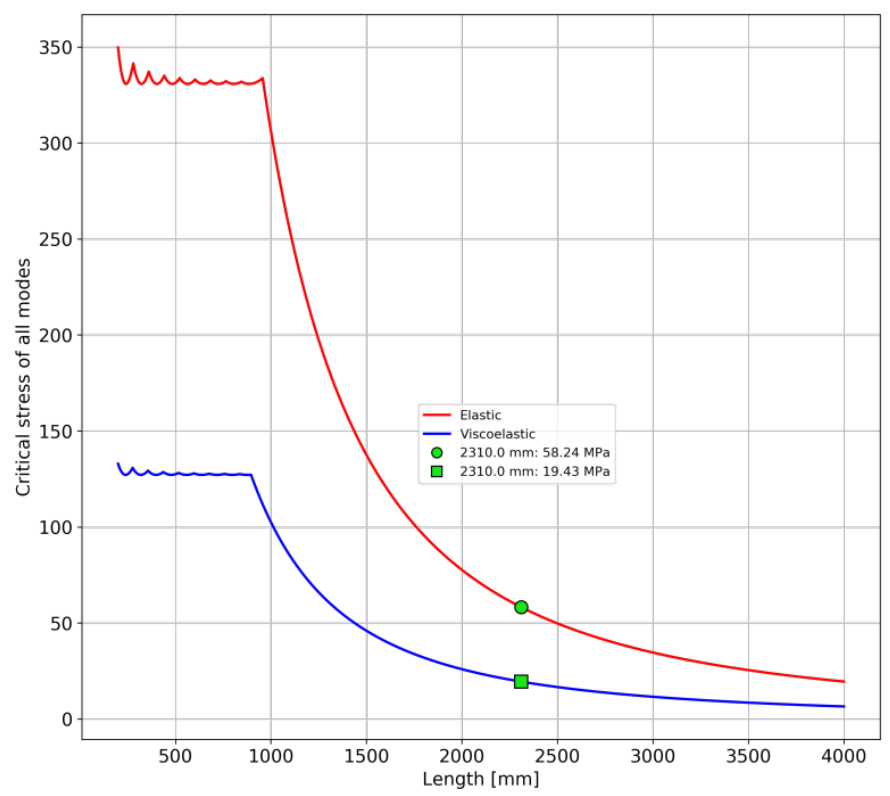

Figure 11: Elastic and viscoelastic critical stresses.

Viscoelastic buckling stress lags behind the elastic buckling stress across all modes, which is a consequence of the viscoelastic behaviour of materials. The viscoelastic behaviour is characterized by the delay time $T^{D}$. As the length of the column is larger, the observed lag increases.

Due to lag, the same column length does not always correspond to the same mode at the elastic and viscoelastic critical stress. However, at the column length of $2310 \mathrm{~mm}$, the computed elastic critical stress of the first mode corresponds to test results [23]. Also, the computed viscoelastic stress at $2310 \mathrm{~mm}$ of the first mode has been previously confirmed in [7].

Fig. 12 shows the natural frequencies computed, as explained in Section 2.2, for the discussed column lengths. The frequency curves have jumps at the end of examined column length intervals, in contrast to the buckling curves. Such jumps within frequency curves are noticeable in both the elastic and viscoelastic solutions.

Also, there is a noticeable lag between the viscoelastic and the elastic natural frequencies, analogue to the described critical stress behaviour. 


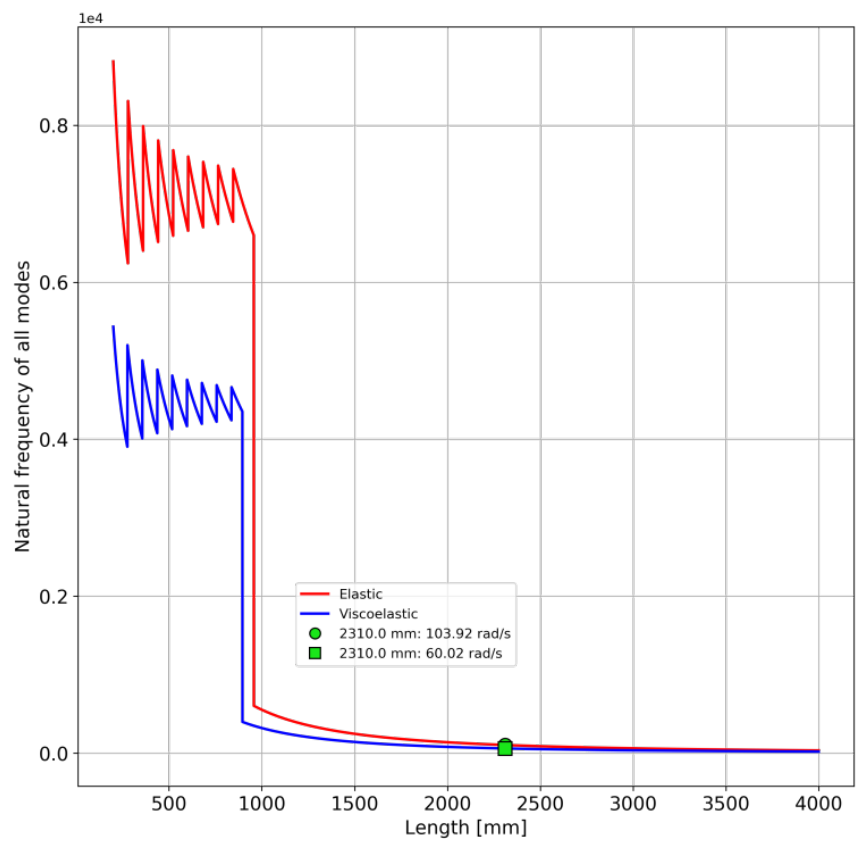

Figure 12: Elastic and viscoelastic natural frequencies.

Fig. 13 (a) presents the viscoelastic buckling curve and the viscoelastic frequency curve for all lengths of columns from 200 to $4000 \mathrm{~mm}$. It is obvious that the solutions of viscoelastic critical stresses and natural frequencies are fully aligned in modes. The viscoelastic solutions are shown in Fig. 13 (b), for the columns length from 200 to 1000 $\mathrm{mm}$. It is clearly seen that the jumps of natural frequencies are always at the lengths of the columns on which the buckling curve has mode intersections. 
(a)

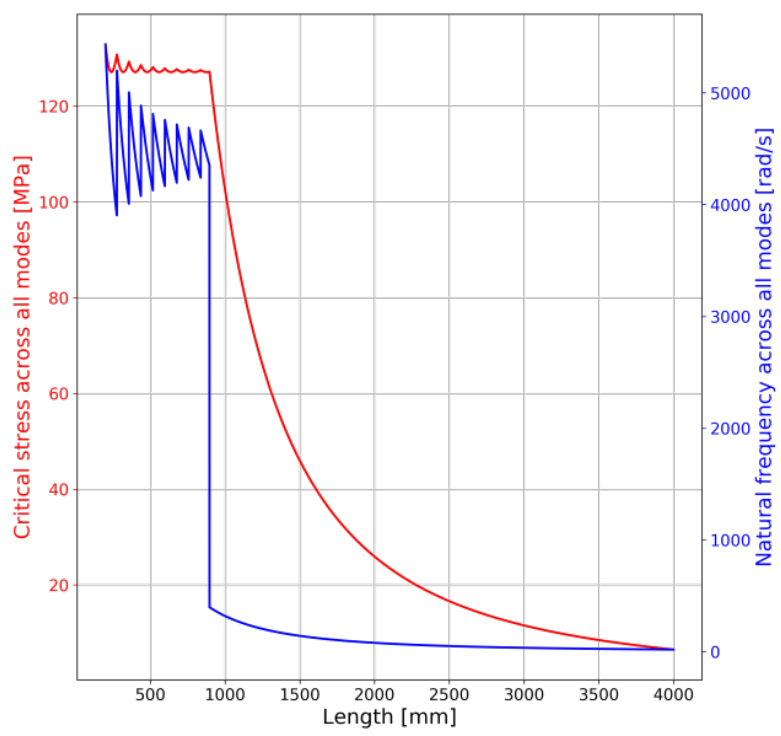

(b)

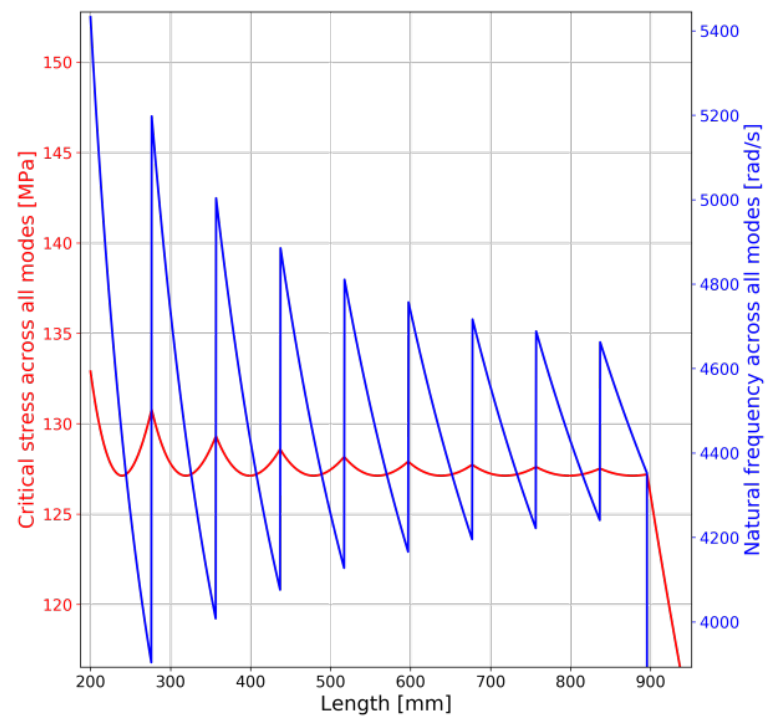

Figure 13: Viscoelastic critical stresses and natural frequencies: (a) for column lengths from 200 to $4000 \mathrm{~mm}$, (b) for column lengths from 200 to $1000 \mathrm{~mm}$. 


\section{$7^{\text {th }}$}

Contemporary achievements in civil engineering 23-24. April 2019. Subotica, SERBIA

Fig. 14 compares the values of viscoelastic critical stresses as solved by the eigenvalue problem and the stresses as computed by applying the natural frequencies in Eq. (22) (physical duality).

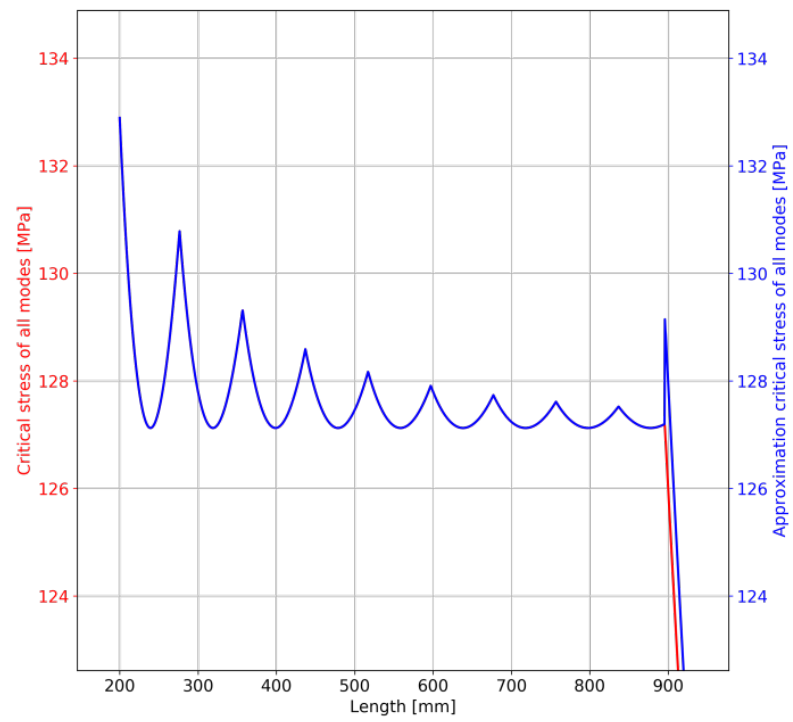

Figure 14: Viscoelastic critical stresses computed applying physical duality.

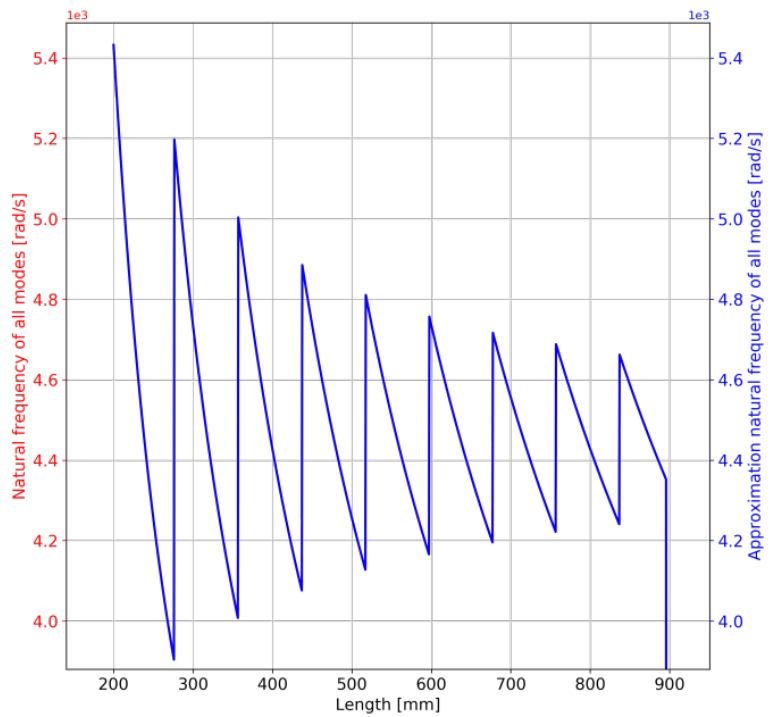

Figure 15: Viscoelastic natural frequencies computed applying physical duality. 
Савремена достигнућа у грађевинарству 23-24. април 2019. Суботица, СРБИЈА

Fig. 15 compares the values of viscoelastic natural frequencies as solved by the eigenvalue problem and the frequencies as computed by applying the critical stresses in Eq. (22).

Fig. 16 presents the relative errors between the solutions as obtained by the eigenvalue problem and the solutions as computed by Eq. (22). The relative error of critical stresses is higher that the relative error of natural frequencies, because the buckling curve is curve of a higher order than the natural frequencies curve. The maximum relative error of only $1.6 \% / 0.8 \%$ (at the approx. $957 \mathrm{~mm}$ ) confirms the physical duality approach and effectively shows that it is sufficient to solve the eigenvalue problem only for the natural frequencies, while the critical stresses may be accurately computed through the equation of physical duality.

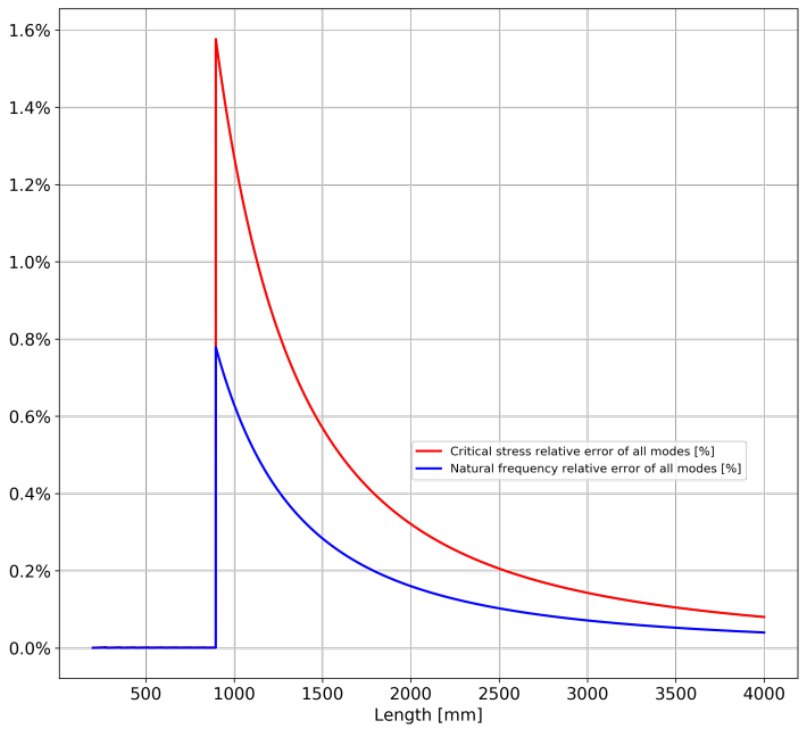

Figure 16: Relative errors obtained applying physical duality.

It is well recognized that when using exact theory or semi-analytical FSM, as opposed to the more usual approximate finite element method, there exists a duality between buckling and natural vibration of an elastic structure, even though the former is a static problem whereas the latter is a dynamic one. The solution procedures for both problems are analogous because both can be essentially represented by a transcendental eigenvalue problem, the eigenvalues being natural frequencies in vibration problems and load factors in buckling problems. Thus the elastic buckling of a structure is often regarded as the degenerated case of its natural vibration at zero frequency. In this paper duality is proved for the both elastic and viscoelastic (or damage) structure using the RDA. 


\section{$7^{\text {th }}$}

Contemporary achievements in civil engineering 23-24. April 2019. Subotica, SERBIA

Fig. 17 presents the results of the delay time on all lengths of columns from 200 to 4000 $\mathrm{mm}$. The results are logical since delay time increase with the increase of length of the columns. The delay time curve is easily obtained as inverse curve from the curve of natural frequency.

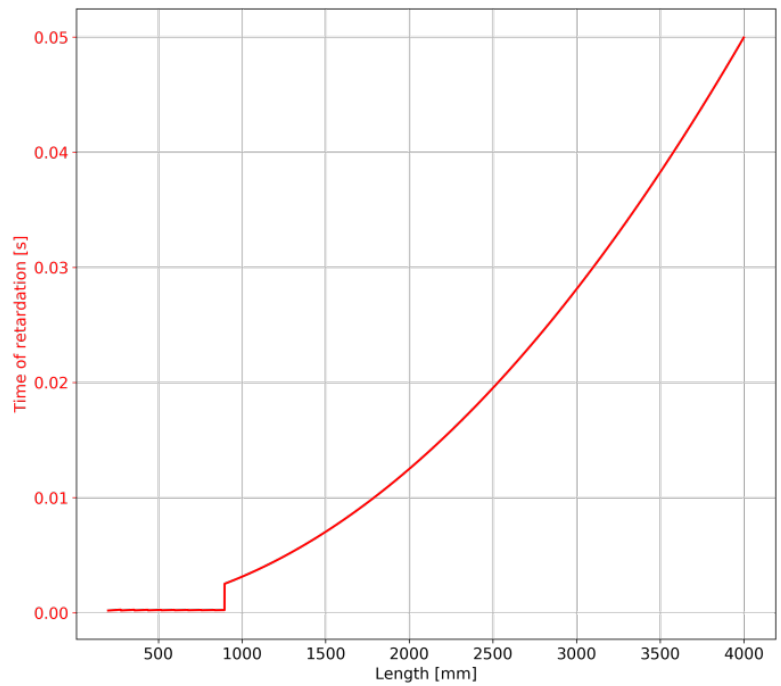

Figure 17: Delay time curve for column lengths from 200 to $4000 \mathrm{~mm}$.

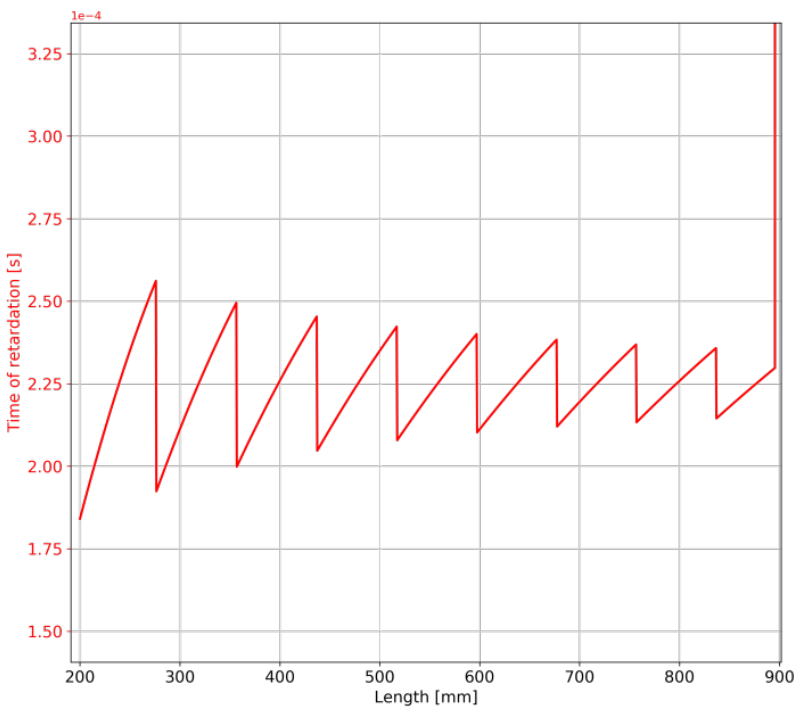

Figure 18: Delay time curve for column lengths from 200 to $900 \mathrm{~mm}$. 
Савремена достигнућа у грађевинарству 23-24. април 2019. Суботица, СРБИЈА

Fig. 18 contains a delay time curve on the lengths of columns from 200 to $900 \mathrm{~mm}$. It is obvious that delay time curve is a sawtooth wave function, divided into segments between modes. Delay time segment peaks shorten when column lengths transition from lower to higher modes. However, the delay time is suddenly increased once the column transitions from the last local mode to the first global mode, because the total column length is engaged in the first global mode. This also causes a sharp increase both in the damage variable and the inelastic effective stress.

Fig. 19 shows the damage variables (Eq. 38) on all column lengths from 200 to 4000 $\mathrm{mm}$. The damage variables fall off for lengths where the column transitions from lower to higher modes. The damage variables fall off is greatest when transition occurs from the first to the second local buckling mode. The other falls become smaller with each successive transition to the next higher local mode.

At the column length of the $957 \mathrm{~mm}$ the column transition from the highest reached local buckling mode into the first global buckling mode occurs. Simultaneously, the damage variable jumps to the maximum value of $\square 1$, which means that the column does not survive this transition and fails instead. This behaviour correlates with the delay, as previously described.

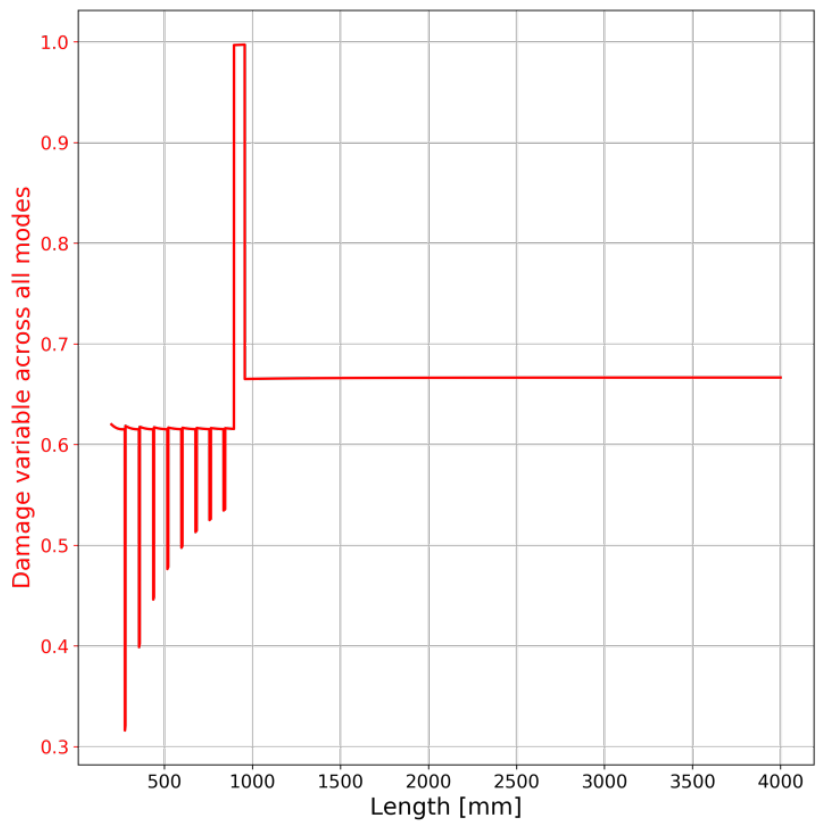

Figure 19: Damage variables for all analysed column lengths.

Fig. 20 shows inelastic effective stresses (Eq. 41) that correlate with the calculated damage variables and follow the abrupt changes of its function. 
Contemporary achievements in civil engineering 23-24. April 2019. Subotica, SERBIA

It should be noticed, Figs. 19 and 20, that at lengths larger than $957 \mathrm{~mm}$ there are no more abrupt changes in any of the described physical properties, although the delay time constantly increases, as shown in Fig. 17. This is due to the absence of mode interaction between elastic and viscoelastic columns at lengths higher than $957 \mathrm{~mm}$. After this length, the columns stay into the same (first) global buckling mode.

In conclusion, this proves that the leaping changes of discussed physical properties are solely a consequence of the columns transitioning from one mode to another, whether it's local or global modes.

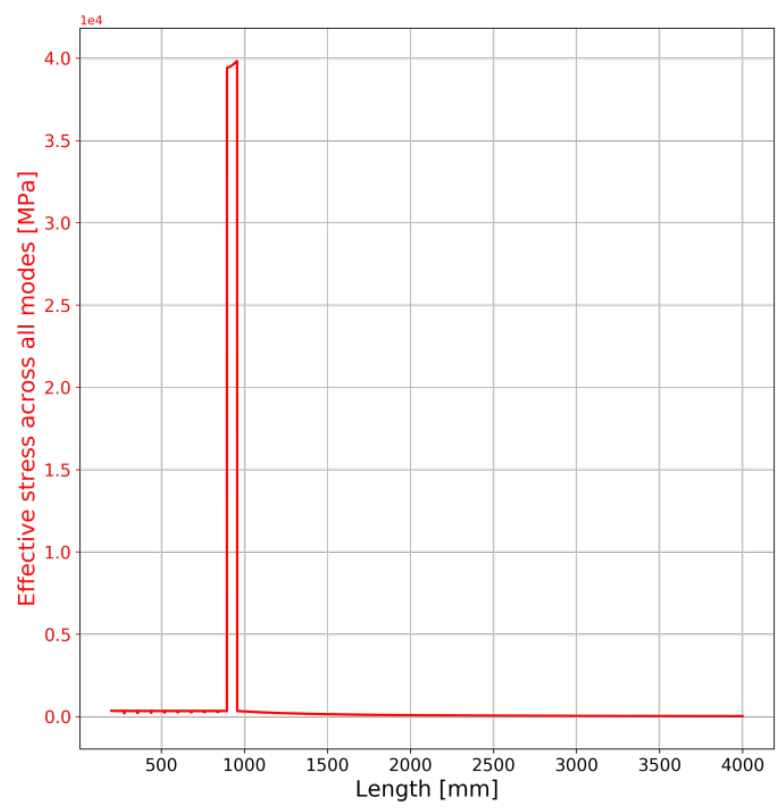

Figure 20: Inelastic effective stresses for all analysed column lengths.

Figs. 21 (a)-(b) show different zoomed-in views of the damage variables on column lengths from 200 to $900 \mathrm{~mm}$, to better display the shape of the function. Fig. 21 (a) shows the function dropping off around mode transitions, whereas Fig. 21 (b) shows the function recovering afterwards. As already stated, this is a consequence of well-known viscoelastic behaviour of materials. 
7. МЕЂУНАРОДНА КОНФЕРЕНЦИЈА

Савремена достигнућа у грађевинарству 23-24. април 2019. Суботица, СРБИЈА

(a)

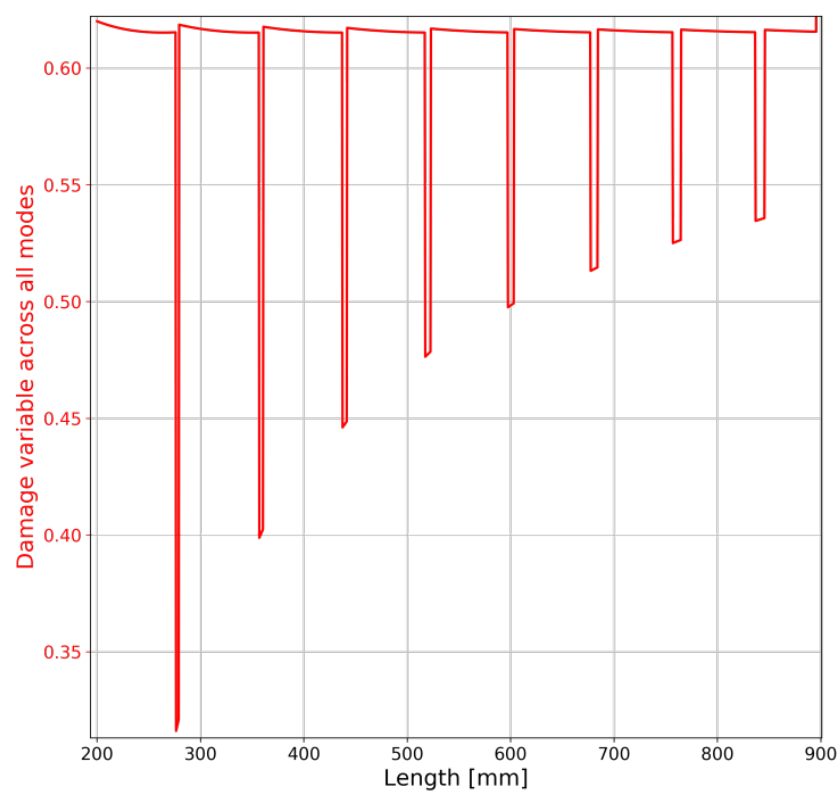

(b)

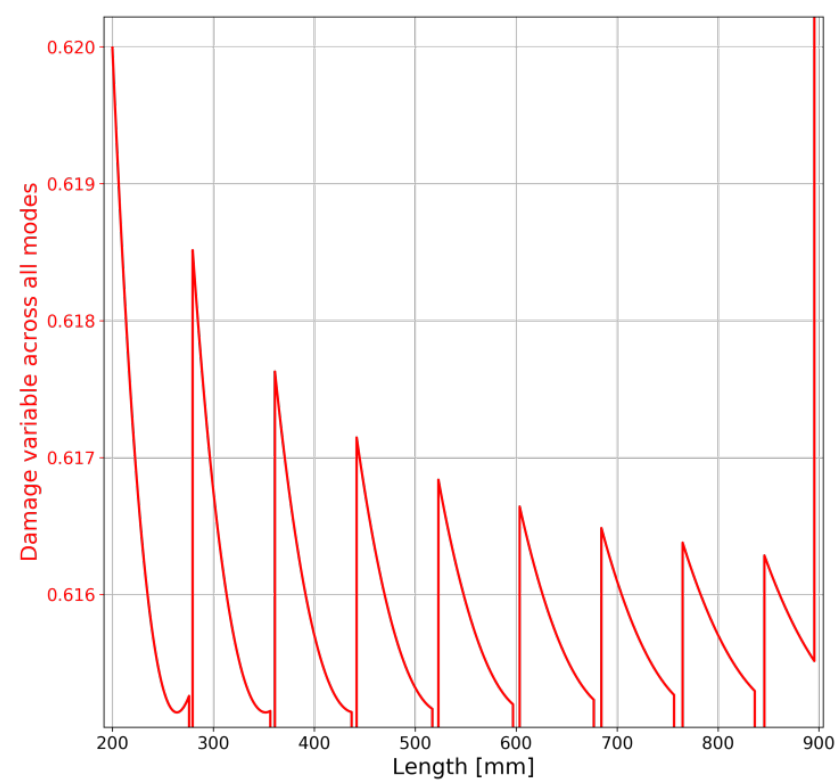

Figure 21: Damage variables, (a) from 0.3 to 0.625, (b) from 0.615 to 0.625. 


\section{$7^{\text {th }}$}

Contemporary achievements in civil engineering 23-24. April 2019. Subotica, SERBIA

Figs. 22 (a)-(b) show inelastic effective stresses calculated on the column lengths from 200 to $900 \mathrm{~mm}$, and its values correlate with the damage variables described above.

(a)

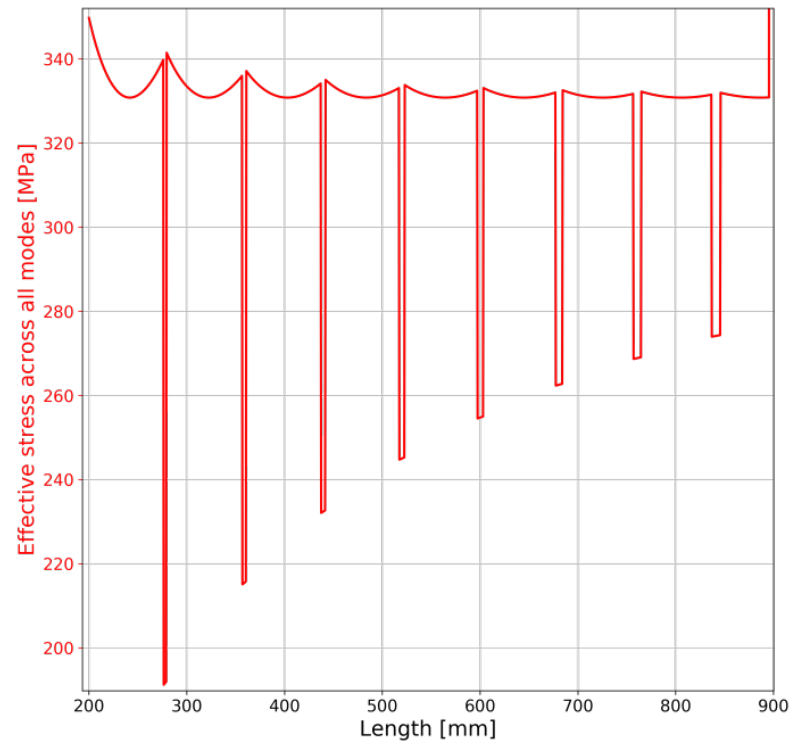

(b)

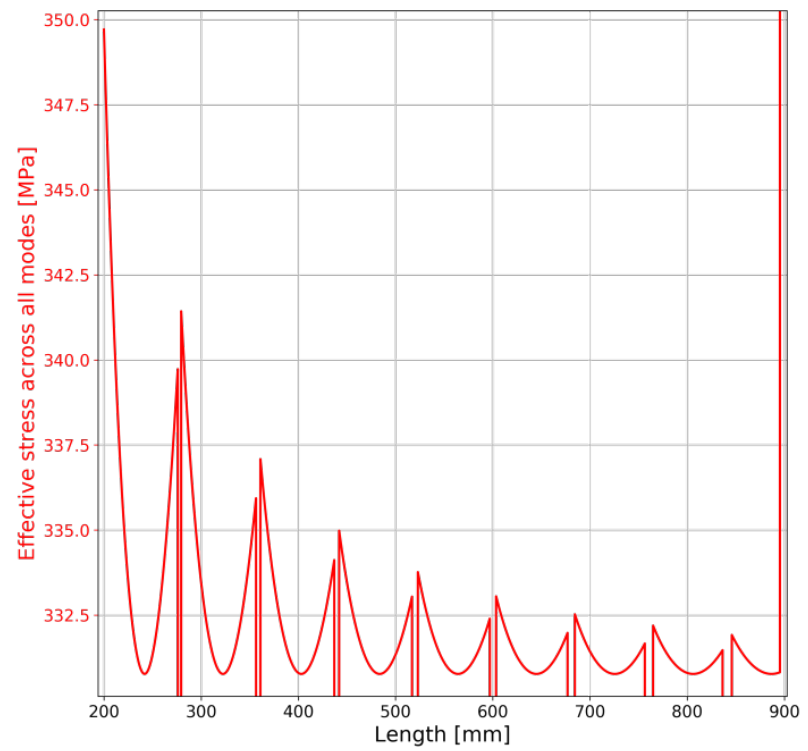

Figure 22: Effective stresses, (a) from 190 to $350 \mathrm{MPa}$, (b) from 330 to $350 \mathrm{MPa}$. 
7. МЕЂУНАРОДНА КОНФЕРЕНЦИЈА

Савремена достигнућа у грађевинарству 23-24. април 2019. Суботица, СРБИЈА

Figs. 23 (a)-(b) overlay Figs. 21 (a)-(b) and Figs. 22 (a)-(b) to directly compare the behaviour of damage variables and inelastic effective stresses.

(a)

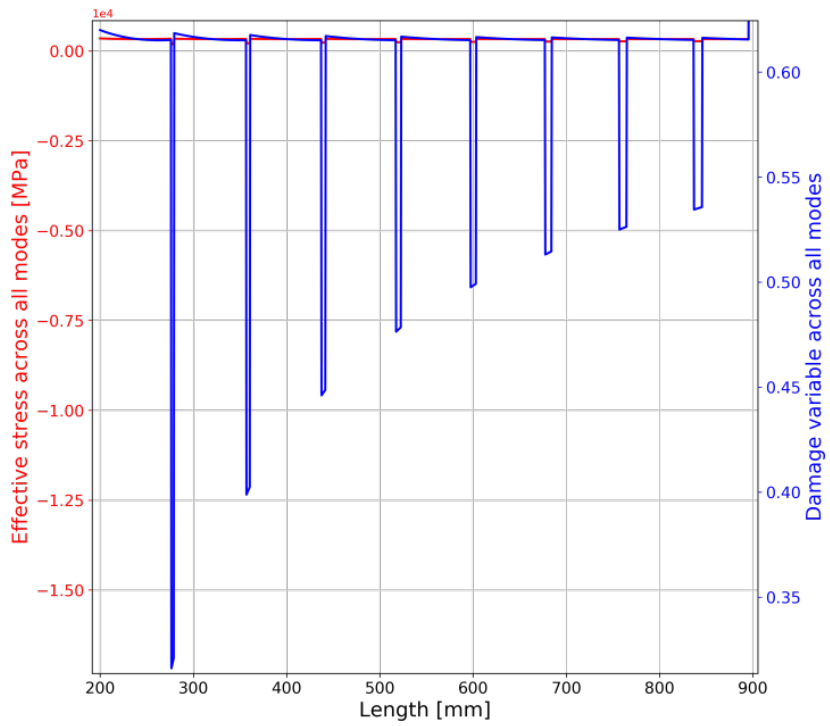

(b)

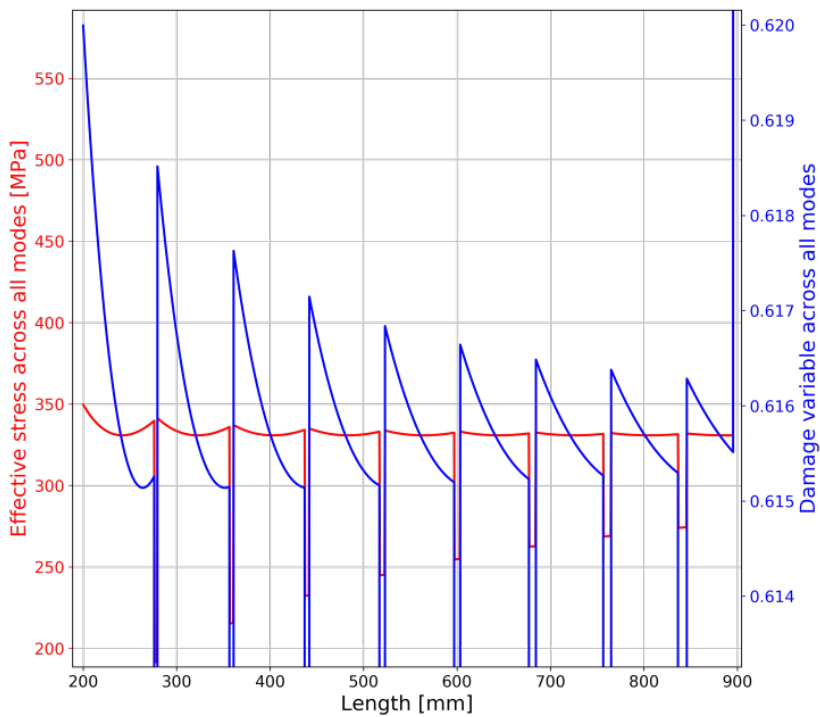

Figure 23 (a)-(b): Comparison of effective stresses and damage variables. 


\section{$7^{\text {th }}$}

Contemporary achievements in civil engineering 23-24. April 2019. Subotica, SERBIA

Finally, Figs. 24 (a)-(b) overlay the elastic critical stress from Fig. 11 and the effective critical stress from Figs. 22 (a)-(b) to directly compare shapes of their functions. Naturally, the effective critical stress matches the elastic critical stress, except around mode transitions - as discussed above.

(a)

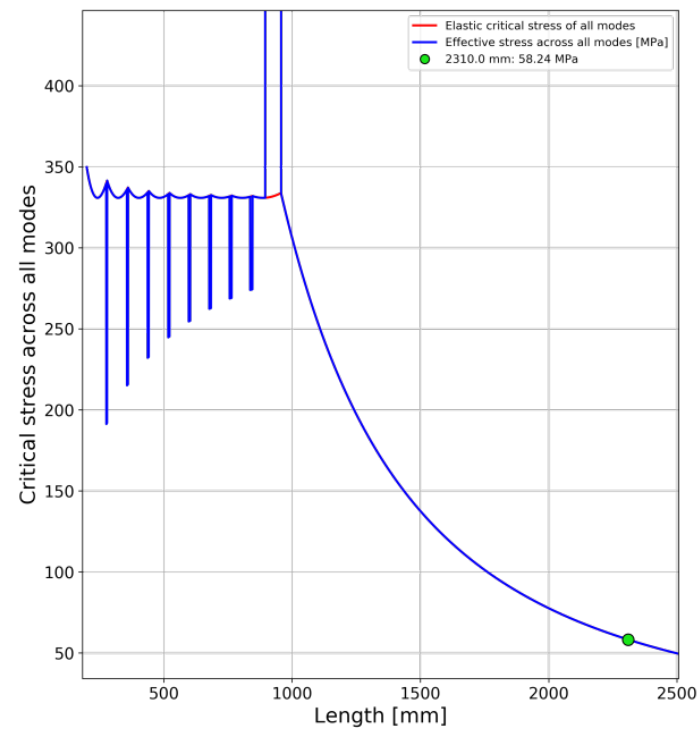

(b)

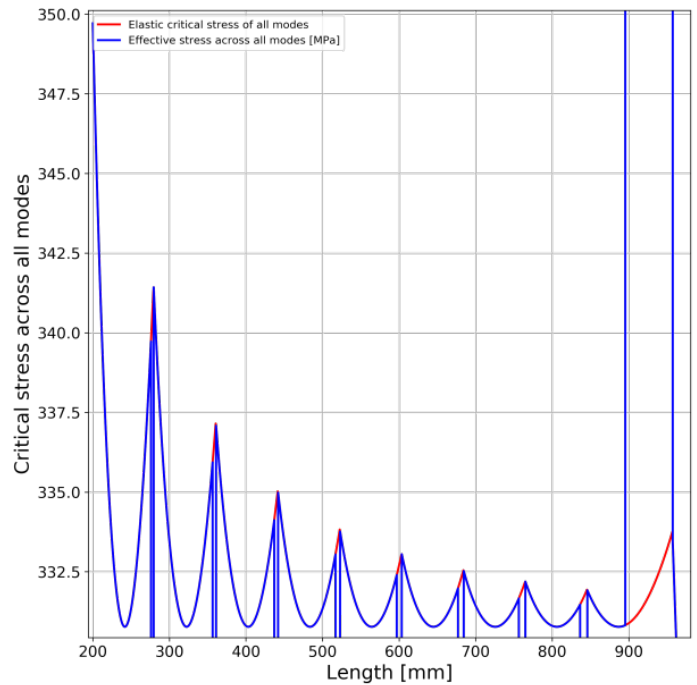

Figure 24 (a)-(b): Comparison of effective and elastic critical stresses. 
Савремена достигнућа у грађевинарству 23-24. април 2019. Суботица, СРБИЈА

\section{RESULTS AND DISCUSSION}

The interaction of more than one local buckling modes, as well interaction between the local and global modes and their influence on effective stresses, is the objective of this investigation. Results from the numerical studies for the three observed column lengths of the local modes are shown in Fig. 25.
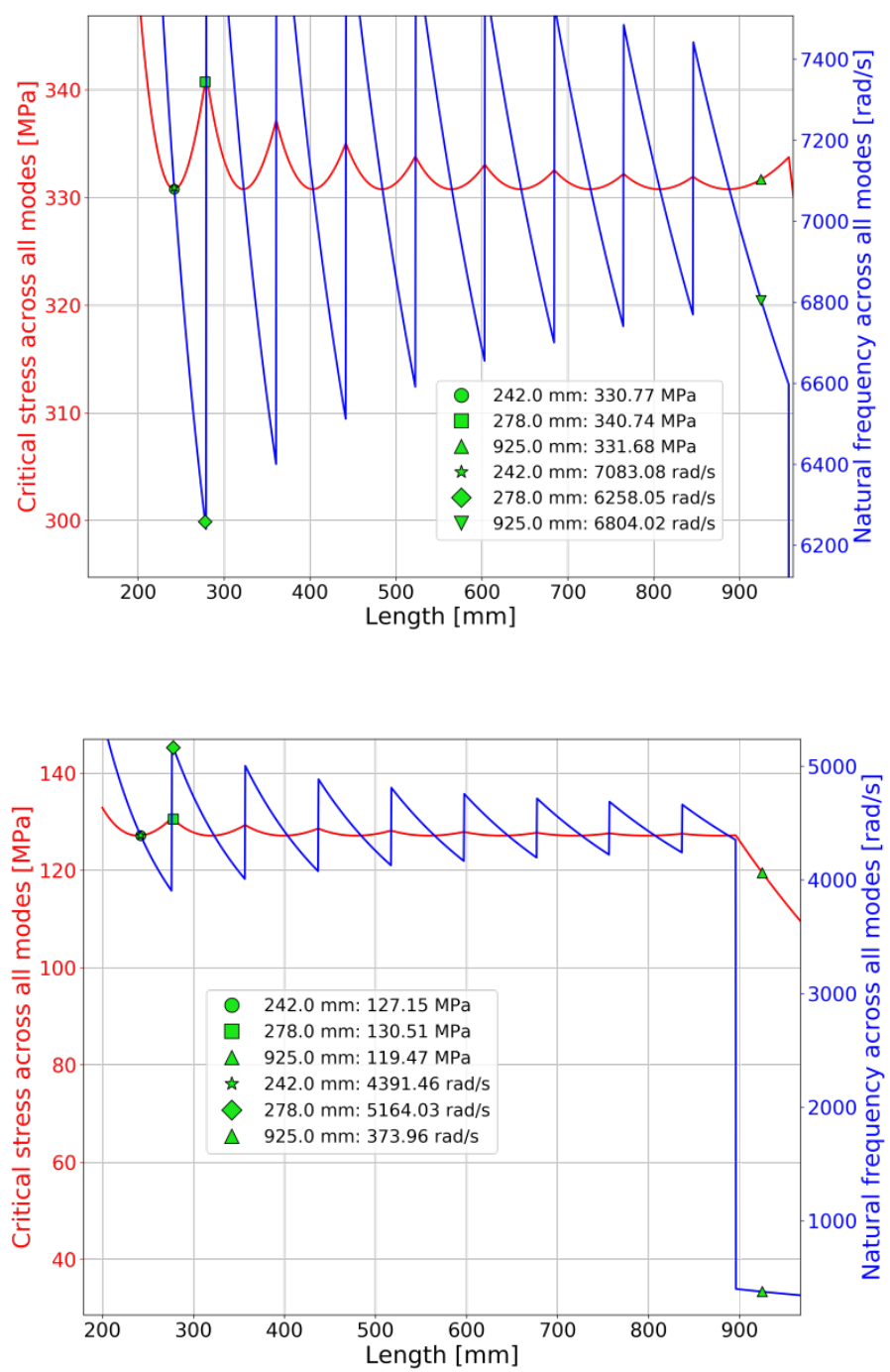

Figure 25: Results from the numerical studies for the three observed column lengths of $242 \mathrm{~mm}, 278 \mathrm{~mm}$ and $925 \mathrm{~mm}$ : (up) elastic, (down) viscoelastic. 


\section{$7^{\text {th }}$}

Contemporary achievements in civil engineering 23-24. April 2019. Subotica, SERBIA

Results of buckling effective stresses for the four observed column lengths are summarized in Table 4.

Table 4: Results of buckling effective stresses for the four observed column lengths

\begin{tabular}{|c|c|c|c|c|c|c|}
\hline $\begin{array}{c}\text { Column } \\
\text { characteristics }\end{array}$ & $\begin{array}{c}\text { Buckling } \\
\text { mode }\end{array}$ & \multicolumn{2}{|c|}{$\begin{array}{c}\text { Buckling-mode } \\
\text { interaction }\end{array}$} & \multicolumn{2}{c|}{$\begin{array}{c}\text { Buckling-mode } \\
\text { interaction }\end{array}$} & $\begin{array}{c}\text { Buckling } \\
\text { mode }\end{array}$ \\
\cline { 2 - 7 } & Local & Local & Local & Local & Global & Global \\
\hline$a[\mathrm{~mm}]$ & 242 & \multicolumn{2}{|c|}{278} & \multicolumn{2}{|c|}{925} & 2310 \\
\hline mode $(m)$ & 3 & 3 & 4 & 11 & 1 & 1 \\
\hline$\sigma_{c r}[\mathrm{MPa}]$ & 330.77 & 340.74 & 340.74 & 331.68 & 358.41 & 58.24 \\
\hline$\omega[\mathrm{rad} / \mathrm{s}]$ & 7083.08 & 6258.05 & & 6804.02 & & 103.92 \\
\hline$D$ & 0.615 & 0.320 & & & 0.997 & 0.666 \\
\hline$\omega^{d}[\mathrm{rad} / \mathrm{s}]$ & 4391.46 & 5164.03 & & & 373.96 & 60.02 \\
\hline$\sigma_{c r}^{d}[\mathrm{MPa}]$ & 127.15 & & 130.51 & & 119.47 & 19.43 \\
\hline$\tilde{\sigma}[\mathrm{MPa}]$ & 330.78 & & 191.93 & & 39823.33 & 58.24 \\
\hline
\end{tabular}

Interaction between two local or local and global buckling modes occurs in intermediate length columns with near coincident critical stresses. In this case the columns do not have all elastic and inelastic characteristics in the same mode.

If column is in the mode interaction of two local modes $(a=278 \mathrm{~mm})$, the effective stress is smaller than elastic stress.

If column is in the local and global mode interaction $(a=925 \mathrm{~mm})$, the effective stress is much larger than elastic stress. Hence, the interaction between this two buckling modes (local and global) induced instantaneous catastrophic failure.

If there is no mode interaction, columns have all elastic and inelastic characteristics in the same mode, local $(a=242 \mathrm{~mm})$ or global $(a=2310 \mathrm{~mm})$, and effective stresses converge to elastic stresses.

\section{CONCLUSIONS}

Numerical examples presented in this paper show the influence of mode interactions on effective stresses if the dynamic properties in undamaged state as well as in damaged state are used together in the inelastic buckling analysis of thin-walled columns. Numerical examples were computed by application of extensive hybrid parallelization. The mode interactions have great influence on damage variables and effective stresses around mode transitions. In its usual semi-analytical form, the FSM cannot be used to solve the mode interaction problem explained in this paper, because this technique ignores the important influence of interaction of the buckling modes when applied only for undamaged state of structure. 
Савремена достигнућа у грађевинарству 23-24. април 2019. Суботица, СРБИЈА

\section{Acknowledgements}

The work presented in this paper is a part of the investigation conducted within the research projects OI 174027 "Computational Mechanics in Structural Engineering" and TR 36017 "Utilization of by-products and recycled waste materials in concrete composites for sustainable construction development in Serbia: investigation and environmental assessment of possible applications", supported by the Ministry of Science and Technology, Republic of Serbia. This support is gratefully acknowledged.

\section{REFERENCES}

[1] Y.K. Cheung, "Finite strip method in structural analysis”, Pergamon Press, 1976.

[2] S. Wang, D.J. Dawe, "Finite strip large deflection and post-overall-buckling analysis of diaphragm-supported plate structures”, Computers and Structures, 61(1), 155-170, 1996.

[3] H. Naderian, M.M.S. Cheung, Z. Shen, E. Dragomirescu, "Integrated finite strip analysis for long-span cable-stayed bridges”, Computers and Structures, 158, 82-97, 2015.

[4] Y.B. Kwon, G.J. Hancock, "A nonlinear elastic spline finite strip analysis for thin-walled sections”, Thin-Walled Structures, 12(4), 295-319, 1991.

[5] D.D. Milašinović, "The finite strip method in computational mechanics", Faculties of Civil Engineering: University of Novi Sad, Technical University of Budapest and University of Belgrade: Subotica, Budapest, Belgrade, 1997.

[6] D.D. Milašinović, "Geometric non-linear analysis of thin plate structures using the harmonic coupled finite strip method”, Thin-Walled Structures, 49(2), 280-290, 2011.

[7] D.D. Milašinović, "Harmonic coupled finite strip method applied on buckling- mode interaction analysis of composite thin-walled wide-flange columns", Thin-Walled Structures, 50(1), 95-105, 2012.

[8] A. Borković, S. Kovačević, D.D. Milašinović, G. Radenković, O. Mijatović, V. GolubovićBugarski, "Geometric nonlinear analysis of prismatic shells using the semi-analytical finite strip method", Thin-Walled Structures, 117, 63-88, 2017.

[9] P.S. Rakić, D.D. Milašinović, Ž. Živanov, Z. Suvajdžin, M. Nikolić, M. Hajduković, "MPICUDA parallelization of a finite-strip program for geometric nonlinear analysis: A hybrid approach”, Advance in Engineering Software, 42, 273-285, 2011.

[10] M. Nikolić, M. Hajduković, D.D. Milašinović, D. Goleš, P. Marić, Ž. Živanov, "Hybrid MPI/OpenMP cloud parallelization of harmonic coupled finite strip method applied on reinforced concrete prismatic shell structures”, Advance in Engineering Software, 84, 55-67, 2015.

[11] D.D. Milašinović, "Rheological-dynamical analogy: modeling of fatigue behavior", International Journal of Solids and Structures, 40(1), 181-217, 2003.

[12] D.D. Milašinović, "Rheological-dynamical analogy: prediction of damping parameters of hysteresis damper”, International Journal of Solids and Structures, 44(22-23), 7143-7166, 2007.

[13] D.D. Milašinović, "Rheological-dynamical analogy: design of viscoelastic and viscoplastic bar dampers", Mechanics of Time-Dependent Materials, 14(4), 389-409, 2010.

[14] D.D. Milašinović, "Rheological-dynamical continuum damage model for concrete under uniaxial compression and its experimental verification”, Theoretical and Applied Mechanics, 42(2), 73-110, 2015.

[15] J. Lemaitre, "How to Use Damage Mechanics”, Nuclear Engineering and Design, 80, 233245, 1984.

[16] I.E. Harik, R. Ekambaram, "Seminumerical solution for buckling of rectangular plates", Computers \& structures, 23(5), 649-655, 1986.

[17] M.A. Bradford, M. Azhari, "Buckling of plates with different end conditions using the finite strip method”, Computers \& structures, 56(1), 75-83, 1995. 


\section{$7^{\text {th }}$}

INTERNATIONAL CONFERENCE

Contemporary achievements in civil engineering 23-24. April 2019. Subotica, SERBIA

[18] P. Maric, D.D. Milašinovic, D. Goleš, Ž. Živanov, M. Hajdukovic (2017), "A Hybrid Software Solution for the Harmonic Coupled Finite Strip Method Characteristic Equations", in P. Iványi, B.H.V. Topping, G. Várady, (Editors), Proceedings of the Fifth International Conference on Parallel, Distributed, Grid and Cloud Computing for Engineering, Civil-Comp Press, Stirlingshire, UK, Paper 31, 2017. doi:10.4203/ccp.111.31.

[19] N.W. Tschoegl, Knauss G. Wolfgang, I. Emri. “ Poisson’s ratio in linear viscoelaticity - a critical review”. Mechanics of Time-Dependent Materials, 6, 3-51, 2002.

[20] J.B. Kosmatka, J.M. Ricles, "Damage detection in structures by modal vibration characterization”, Journal of Structural Engineering. 125(12), 1384- 1392, 1999.

[21] D.D. Milašinović, A. Landović, "Rheological-dynamical analogy for analysis of vibrations and low cycle fatigue in internally damped inelastic frame structures”, Computers and Structures, 196, 76-93, 2018.

[22] S. Murakami, “Continuum Damage Mechanics”, Springer Dordrecht Heidelberg London NY, 2012.

[23] E.J. Barbero, E.K. Dede, D. Jones, "Experimental verification of buckling-mode interaction in intermediate-length composite columns”, Int. J. Solids and Structures, 37(29), 3919-3934, 2000.

[24] E. Barbero, J. Tomblin, “A Phenomenological Design Equation for FRP Columns with Interaction between Local and Global Buckling”, Thin-Walled Structures, 18, 117-131, 1994. 